Eleonore De Felip

\title{
Oswald Eggers Val di Non oder Die Zusammenverbundenheit der Untal-Intervalle
}

\section{Cover und Klappentext}

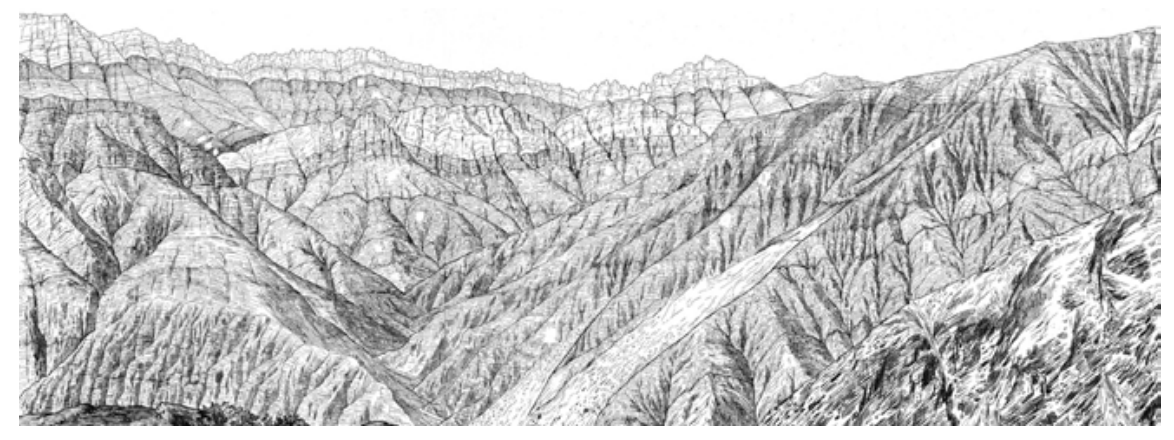

Abb. 1: Egger 2017, Cover.

Oswald Eggers Val di Non (2017) ist ein Buch von ungewöhnlicher, rätselhafter Schönheit. ${ }^{1}$ Das Cover zeigt die kartographische Illustration eines Bergmassivs: In den Weißraum des Deckblatts ragt streng und düster eine majestätische Gebirgskette. Zentral im Vordergrund öffnet sich der Berg zu einem V-förmigen Tal. Die vielen feinen Linien und Schraffuren suggerieren das zerklüftete Profil des Gebirges. Mit naturwissenschaftlicher Präzision sind hier alle Sedimentschichten des Gesteins, Schneefelder, Rinnen, Geröllhalden, Schluchten und feinste Seitentäler optisch erfasst. Doch bedeckt keine Vegetation die kahlen Hänge. $\mathrm{Zu}$ sehen ist nur das nackte Gestein und auf ihm die Spuren einer glazialen Vergangenheit. Es ist ein Berg ohne seine lebende Hülle, gewissermaßen ein Berg im statu nascendi. Knapp über dem Gebirgskamm steht in orangen Lettern (an eine auf- oder untergehende Sonne erinnernd) der Titel: Val di Non. Über dem Gebirge öffnet sich der >Himmel als großes, weißes Nichts. Auch zwi-

1 Ich danke den Herausgebern Ralf Simon und Martin Endres für ihre Einladung, an diesem Band mitzuarbeiten, und für ihre wertvollen Anregungen.

Eleonore De Felip, Innsbruck 
schen den feinen Linien der Zeichnung öffnen sich Zwischenräume, unzählige Leerstellen. Je genauer wir das Bild betrachten, umso klarer erkennen wir das dem Berg inhärente Nichts. Nun, wer jemals selbst im wirklichen Val di Non war, wundert sich. Das orographisch rechte Seitental der Etsch, dessen weitaus größter Teil in der Provinz Trentino (dem historischen Welschtirol) liegt, dessen nördlichster, deutschsprachiger Teil aber (seit 1948 wieder) zur heutigen Provinz Südtirol gehört, hat nichts von der hier unterstellten Düsterkeit. Es ist ein grünes Tal von suggestiver Schönheit, das für seine duftenden Äpfel und seine in prähistorische Zeiten zurückreichende Siedlungsgeschichte bekannt ist. Ein Blick auf die bibliographischen Angaben am Ende des Buches erklärt die Diskrepanz zwischen Bild und Titel: Tatsächlich handelt es sich hier um eine Illustration aus der wissenschaftlichen Zeitschrift Memoirs of the Geological Survey of India aus dem Jahr 1891. Der auf dem Cover von Val di Non dargestellte Berg steht in Indien.

Dieser auf dem Deckblatt inszenierte, zugegebenermaßen kaum merkliche, wohl nur für die Kenner der realen geographischen Gegebenheiten des Val di Non spürbare Widerspruch zwischen Titel und Illustration kann als poetisches Programm gelesen werden. Das Bild steht zum Wort in keinem abbildenden Verhältnis. Es dient der Öffnung und Weitung des vordergründigen Sinns und steht für dessen verborgene Dimensionen. Es hat eine gewisse entfernte Ähnlichkeit mit dem nördlichsten, von Bergen und Schluchten gekennzeichneten Teil des Val di Non, doch ist die Ähnlichkeit keine naheliegende, sondern eine durch Imagination erst zu schaffende. Es bedarf eines mentalen Brückenschlags, guter geographischer Vorkenntnisse, eines entwickelten Abstraktionsvermögens sowie einer lebhaften Phantasie. Wer in Eggers Buchwelt eintritt, muss bereit sein, einen aktiven Part zu übernehmen, muss sich Zeit nehmen, sich auf ein unbekanntes Tal einzulassen, dessen Sinn nur in einem langsamen Leseprozess erschlossen werden kann. ${ }^{2}$ Die 'wirkliche` Welt des Val di Non mit ihren geologischen, sprachlichen und mythologischen Besonderheiten wird von den möglichen Welten poetisch imaginierter Täler wie von multiplen Stratosphären umhüllt.

2 Wolfram Schütte (2013) spricht anlässlich des 250ten Geburtstags von Jean Paul von der Notwendigkeit einer langsamen »vertikalen« Lesehaltung, da nur sie den Blick für die Tiefenschichten der Jean-Paul'schen Prosa befähige: »Man kann ja die `Les(e)art` von Belletristik generell in zwei Formen sehen: Eine für `Leseratten`flugs von Satz zu Satz eilende, von Spannungsbögen \& Aktionen \& Handlungsvolten motivierte Leser-Haltung, die gewissermaßen horizontal verläuft. Und eine andere, die im Vergleich dazu als vertikal bezeichnet werden kann, weil sie vom Leser ein nachdenkendes Verweilen beim jeweiligen Satz und Wort verlangt, um die dort vom Autor in der Redundanz der schriftlichen Artikulation niedergelegten Bedeutungsschichten, Metaphern, Allegorien, Assonanzen etc. sowohl zu entdecken als auch auszukosten.« Diese Lesehaltung ist beim Jean-Paul-Verehrer Oswald Egger ebenso angesagt. 
Die >Wirklichkeit des Egger'schen Val di Non erweist sich im Laufe der Lektüre als die Summe vieler denkbarer Täler. Das Universum des Val di Non umfasst die ins Dunkel der Vergangenheit versunkenen einstigen Realitäten sowie alternative, im Bereich des Möglichen angesiedelte Wirklichkeiten. Diese ızweiten (nicht-tatsächlichen) Welten stehen zur sersten` (tatsächlichen) Welt in einem Verhältnis der Erreichbarkeit. ${ }^{3}$ Es verbinden sie Ähnlichkeiten oder aber: Sie bilden (miteinander kontrastierende) Teile eines notwendigen Ganzen.

Ein Berg, ein Tal, ein Bild, ein Buchtitel - was verbindet sie? Und ist den Verbindungen zu trauen?

Wer umblättert, liest im Klappentext: ${ }^{4}$

Ist es möglich, einen Berg zu denken, zu dem das Tal fehlt? Wenn man sich Gott und die Welt vorstellen kann, kann man sich z. B. nicht Gott ohne die Welt vorstellen: Was einem vorschwebt, von A bis Z, erscheint oft realer als das, was vor Augen bloß irritiert. Einmal waren Berge Berge, die Täler waren Täler. Nachdem es mehr Dinge zwischen Grund und Grat gibt, als wir träumen können, sind Berge weder Berge noch Abgründe Abgründe: Was einem blüht, mag zugleich auch blühendes Tal sein. In aller Stille rufen Laute einander auf und zu, kaum wahrnehmbar noch, tief von innen und unten. Nachtwach, in Sprache, schwellen die Intervalle an, stets fügt sich eine zweite Stimme zur ersten, dann noch eine, und dann noch und noch: wie ein Echo das Offene durch Wiederholung der Beschränkung auskostet, aber auf immer weniger Wirklichkeit trifft.

Dass es möglich ist, »einen Berg zu denken, zu dem das Tal fehlt«, bestätigt der Sprachgebrauch der Bewohner des wirklichen Tals: Val di Non ist sein italienischer Name. Das analoge deutsche Nonstal ist eine Neuprägung jüngsten Datums. Es steht auf touristischen Seiten im Internet, wohl um Verwirrungen vorzubeugen. Die alte deutsche, historische Bezeichnung aber lautet Nonsberg. Mit Nonsberg bezeichnen die Südtiroler das gesamte Tal inklusive der umgebenden Berge. Der nördlichste (im Südwesten Südtirols gelegene) Teil der Tallandschaft mit den vier deutschsprachigen Dörfern Laurein, Proveis, St. Felix und Unsere Liebe Frau im Walde wird von den Südtirolern noch immer Deutschnonsberg genannt, um ihn vom welschen (italienischsprachigen) Nonsberg $\mathrm{zu}$ unterscheiden. Früher (wie alte Urkunden bezeugen) hieß dieser Teil noch Deutschgegend. ${ }^{5}$ In Egon Kühebachers Werk Die Ortsnamen Südtirols und ihre Geschichte findet man im zweiten Band Die geschichtlich gewachsenen Namen der Täler, Flüsse, Bäche und Seen den Nonsberg unter dem Begriff Deutschgegend: "Damit bezeichnet man die obersten

3 Ich übernehme hier das Bild von Marie-Laure Ryan (2013).

4 Der `Sound` des Klappentexts (Lexik, Syntax, `Logik`) lässt vermuten, dass er vom Autor selbst stammt.

5 Zur Sprachgeschichte des Deutschnonsbergs: Kollmann 2012. 
Zonen der Bäche Pescara (s. Pescarabach/Fischbach) und Novella, die in den Noce münden.«(Kühebacher 1995, 48)

Es gibt also eine sprachgeschichtliche Erklärung zu einem unwirklich klingenden Satz. Der traditionellen Namensgebung der Südtiroler entsprechend bezeichnet >Berg، ein Tal:

Im Gebirgsland Tirol wird [...] das Wort Berg nie zur Bezeichnung eines Berggipfels verwendet, sondern benennt das Gelände zwischen der Talsohle und der Vegetationsgrenze. Unter Berg versteht man also die Siedlungen über der Talniederung, die Wälder, Almen, Bergmähder, Weidegebiete über der Waldgrenze und alle Hochgelände, die noch irgendwie wirtschaftlich genutzt werden. Das unfruchtbare Gebiet darüber, auf dem außer einigen Hochgebirgsblumen und Moosflechten nichts mehr wächst und das folglich für die bäuerliche Wirtschaft bedeutungslos ist, war bis ins Zeitalter des Alpinismus weitgehend namenlos.

(Kühebacher 2007, 47)

Alle Niederungen hingegen bezeichnen die Südtiroler als `Land،. Die Bezeichnungen Etschtal, Eisacktal oder auch Inntal sind sprachhistorisch jung (Kühebacher 2007, 52f.).

Berg ist der Gegensatz zu Land. Selbst mit dem Gebrauch des Wortes »Tal, -tal« kann sich die bodenständige Sprache nur wenig anfreunden, obwohl die Siedlungen eines Gebirgslandes doch vorwiegend in Tälern liegen. Der Einheimische sagt Langtaufers, Sulden, Martell, Schnals, Passeier, Ulten, Pfitsch, Schalders, Lüsen, Afers, Vilnnöß, Gröden, Sexten, Prags, Gsies, Antholz usw. und hängt nie ein »Tal, -tal« an; das ganze Tal heißt Passeier, Prags, Schnals, Antholz usw., man geht »ins Passeier, Prags, Schnals, Antholz und nicht »ins Passeiertal, Pragser Tal, Schnaltal, Antholzer Tal«.

(Kühebacher 2007, 52)

Der obere Verlauf der Etsch zwischen dem Reschen und Meran heißt Vinschgau, das Land um Meran heißt Burggrafenamt, das Etschtal zwischen Meran und Bozen Oberland, jenes südlich von Bozen Unterland und das Land zwischen Eppan und dem Kalterer See Überetsch. Der Autor Oswald Egger stammt aus Lana im Burggrafenamt und nicht aus Lana im Etschtal, wiewohl sein Heimatdorf mit den umliegenden, weiten Apfelgärten unmittelbar an der Etsch liegt. Lana liegt am Fuße des Nonsbergs, der als Hausberg der Lananer ein integraler Bestandteil ihrer Welt ist.

Der Hauptfluss des Nonsbergs, der Noce, ${ }^{6}$ entspringt am Cevedale und durchfließt zunächst den Sulzberg (ital. Val di Sole), bevor er bei Mestizzólo in einer tiefen Schlucht nach Süden abbiegt und in den Nonsberg einfließt, um schließlich bei Mezzocorona (dt. Kronmetz, s. Kollmann 2012, 30) nördlich von Trient in die

6 Der alte deutsche Name Ulz oder Ulzbach, der in spätmittelalterlichen und frühneuzeitlichen Urkunden belegt ist, wird heutzutage nicht mehr verwendet. S. dazu Kollmann 2012, 23. 
Etsch zu münden. Der Sulzberg ist ein Seitental des Nonsbergs. Im Tirolischen ist es also durchaus möglich, zwei Berge zu denken, denen die Täler fehlen.

Es lohnt sich, bei vielen von Eggers scheinbar unsinnigen Sätzen nach reellen Gegebenheiten zu suchen, die ihnen zugrunde liegen. Was auf den ersten Blick als sprachliche Kuriosität erscheint, hat ihren Grund oftmals in teils vergessenen, teils dialektal sehr spezifischen Sprachphänomenen.

Doch zurück zum Buchumschlag: Warum steht hier Val di Non und nicht Nonsberg? Warum wählt der Autor hier den italienischen Namen, der eindeutig das Tal benennt, und verbindet ihn mit der Zeichnung eines Berges? Vermutlich weil das italienische Val di Non, >wörtlich`genommen, ein >Nicht-Tal`oder >UnTal ist und damit ankündigt, wovon im Buch die Rede sein wird: von einer Landschaft, in der "Berge weder Berge noch Abgründe Abgründe» sind, sondern Linien, die (einen Schnitt durch das Chaos ziehend) zu möglichen (u-topischen $^{7}$ ) Welten führen. Val di Non ist eine »Fluchtlinie« im Sinne von Deleuze und Guattari, die - vom reellen Val di Non ausgehend - Möglichkeiten eines Auswegs aus vorgefertigten Meinungen aufzeigt (Deleuze und Guattari 1996, 233). Eggers Val di Non besingt ein Tal, zugleich die Aufbrüche und Ausbrüche aus einer vorgefertigten Sicht von Berg und Tal, von Heimat und Hausberg, von Sprache und Name und Bild. Es gehe der Kunst darum, so Deleuze und Guattari in Was ist Philosophie?, sich ins Chaos vorzuwagen, das uns Menschen von allen Seiten umgebe und vor dem wir uns mit Konventionen und fixen Meinungen (doxai) abzuschirmen versuchen. Die Kunst sei ein Riss im Schirm der vorgeprägten Meinungen:

[...] der Dichter, der Künstler aber macht einen Schlitz in diesen Schirm, er zerreißt sogar das Firmament, um ein wenig freies und windiges Chaos hereindringen zu lassen und in einem plötzlichen Lichtschein eine Vision zu rahmen, die durch den Schlitz erscheint [...].

(Deleuze und Guattari 1996, 241)

Im Non des Val di Non leuchtet demnach das Chaos herein, vor dem wir uns durch das traditionelle Bild vom Nonsberg zu schützen versuchen.

Die Etymologie von >Non ist unsicher (Kollmann 2012, 24). Erstmals wird das Volk der Anauni auf einer Bronzetafel aus dem Jahr 46 n. Chr. erwähnt. ${ }^{8}$ Der Text verkündet das Edikt des Kaisers Claudius, wonach den im nördlichen Municipium Tridentinum lebenden Völkern der Anauni, Tulliasses und Sinduni das römische Bürgerrecht verliehen wurde (Kollmann 2012, 24). Welche Sprache diese Völker sprachen, ist bis heute nicht ganz geklärt. Sicher scheint zu sein,

7 U, griech. oủ: Verneinungspartikel »nicht, kein«, griech. тóтоৎ: Ort.

8 Diese »tabula clesiana« (sie wurde auf einem Acker in Cles gefunden) ist heute im Museum des Castello del Buonconsiglio in Trient zu sehen. 
dass es eine nicht-indogermanische Sprache mit rätischem Anteil war (Kollmann 2012, 24). Auf dem gesamten Nonsberg wurden etwa 100 rätische Inschriften aus der Zeit der Fritzens-Sanzeno-Kultur gefunden. ${ }^{9}$ Nach der Unterwerfung der Räter durch die Römer ging das Rätische im Vulgärlateinischen und späteren Westromanischen auf. Zahlreiche Tiroler Orts- und Flurnamen haben rätische Wurzeln. Später, in den Wirren der Völkerwanderung, geriet auch der Nonsberg in den Einflussbereich der Ostgoten, Langobarden und Franken. Seit der Langobardenzeit gehörte der Nonsberg zum Herzogtum Trient. In der Sprache der Bewohner des Tals verschmolz das Rätische mit dem Vulgärlateinischen: Es entstand das Nonsberger Rätoromanische oder Noceromanische. ${ }^{10}$ Erst im Mittelalter siedelten sich Adelsgeschlechter aus dem deutschen Etschtal im Nonsberg an.

\section{Fluchtlinien und Intervalle}

Während der folgenden Lektüre der ersten Seiten von Val di Non wird die im Klappentext angekündigte mehrfache Pendelbewegung des Textes vom Wirklichen zum Unwirklichen und retour, vom Tal zum Un-Tal und zurück, untersucht. Ein besonderes Augenmerk gilt dabei den Paratexten und Parabildern, die das poetische Entrée ins reigentlicher (Un-)Tal bilden und als Nachspiel am Ende (auf S. 207) sogar eine Art Lektüreschlüssel bieten. Die Lektüre verbindet hermeneutische, narratologische und intertextuelle Analysemethoden. Durch die sehr genaue Betrachtung einzelner Wörter, Sätze, Verse und Bilder soll gezeigt werden, dass Eggers scheinbar unverständliche poetische Sprache aus einem kreativ-subversiven Umgang mit altem, historisch gewachsenem (zum Teil wieder verschwundenem) und dialektalem `Sprachmaterial sowie aus dem Dialog mit anderen poetischen und philosophischen Stimmen (im Sinne Bachtins) entsteht. Egger erzählt ein Tal neu, indem er dessen Klänge und Klangintervalle sowie die vielfachen Brüche in eine salt-neue`Sprache und in Bilder verwandelt.

Die etymologische Analyse einzelner Wörter, die Rekonstruktion lokaler Sagen und Mythen und geologischer Wirklichkeiten shinter der nur scheinbar verspielten narrativen >Fassade`soll Bedeutungsschichten und -zusammenhänge aufdecken, die den Text als sinnvolles Ganzes, als höchst kunstvolle Komposition erscheinen lassen.

9 Zu den rätischen Inschriften des Nonsbergs Schumacher 1992, 131-153, 220-204.

10 Den Begriff »Noceromanisch« hat Cristian Kollmann (1999) geprägt. 
Die folgende Analyse beleuchtet insbesondere vier Aspekte:

2.1. Eggers Val di Non ist die Übersetzung einer klingenden (Sprach-)Landschaft in ein polyphones Wort-Bild-Kunstwerk: Es ist ein kontrapunktisch komponiertes Epos, dessen Struktur und Melodien sich den >Intervallen` des Hausbergs und der Sprachheimat des Autors verdanken. Die Intervalle sind nicht nur raumzeitlicher, sondern auch qualitativer Art. So wie die orographische Realität des Nonsbergs aus geologisch differenten Substraten, aus verschiedenen Gewässern (und einer wunderbaren, in ihrer Diversität nur noch selten anzufindenden Flora) besteht, so ist auch die sprachliche Landschaft hochkomplex: Es ist eine Grenzlandschaft, in der sich deutsche, rätoromanische und italienische Mundarten berühren. Intervalle öffnen sich nicht nur zwischen den Schichten im Gestein und den historischen Schichten in der Sprache, sondern ganz besonders auch zwischen Wirklichkeit und Traum. (»Was einem blüht, mag zugleich auch blühendes Tal sein.« Egger 2017, Klappentext.) Egger lässt die Laute des rreellen Tals einander zurufen und hört auf ihren Dialog. Er lässt die Intervalle, d. h. Differenzen, wachsen (»Nachtwach, in Sprache, schwellen die Intervalle an [...] « Egger 2017, Klappentext). Daraus ergeben sich Echosı, die nur scheinbar die Laute wiederholen. Vielmehr erzeugen sie neue Stimmen, die das beschränkte Original weiten und öffnen (»wie ein Echo das Offene durch Wiederholung der Beschränkung auskostet, aber auf immer weniger Wirklichkeit trifft.« Egger 2017, Klappentext). Mit jeder Schwingung erfasst das Pendel tiefere und höhere Dimensionen des Denkbaren (Chaos). Es entstehen Fluchtlinien der Imagination. In Val di Non verschmelzen die verschiedenen Grade von Wirklichkeit und Möglichkeit zu Prosatexten, Gedichten und Bildern. Sie sind Chaoiden, ${ }^{11}$ Kinder des Chaos. Val di Non bildet einen »Chaosmos «. ${ }^{12}$

2.2. Das Buch ist ein mixtum compositum aus Prosa und Lyrik, Text und Bild. Es ist die Summe aller Intervalle zwischen Prosa-, Lyrik- und Bildnarration. Val di Non ist ein langer erzählender Gesang, ein Epos, welches den >Ursprung` und die Fülle einer Tal- und Sprachlandschaft singend evoziert. Wenn zu Beginn der >Ursprung، des Baches Novella (Tieftalbach) besungen wird, so wird damit der >Ursprung ^ nicht nur eines Tals, sondern einer ganzen Welt besungen. Egger positioniert sich in der Nachfolge Hesiods, welcher in der Theogonie den Ursprung

11 Deleuze und Guattari 1996, 247: »Kurzum, das Chaos besitzt drei Töchter je nach Ebene, die es schneidet: dies sind die Chaoiden, Kunst, Wissenschaft und Philosophie, als Formen des Denkens oder der Schöpfung."

12 Deleuze und Guattari 1996, 242: »Die Kunst ist nicht das Chaos, wohl aber eine Komposition des Chaos, die die Vision oder Sensation schenkt, so daß die Kunst einen Chaosmos bildet, wie Joyce sagt, ein komponierbares Chaos - weder vorausgesehen noch vorgefaßt.» 
der Welt und der Götter besingt. So wie Hesiod im Prooimion der Theogonie die Musen auf dem Berge Helikon anruft und als seine Inspirationsquelle preist (»Von Helikonischen Musen will ich mein Singen beginnen, / die an dem großen, heiligen Berg, dem Helikon wohnen, / [...]« Hesiod 1991, V. 1-2; »Diese nun lehrten einst auch Hesiodos schöne Gesänge, / als er am Fuße des heiligen Helikon Lämmer gehütet.« Ebd., V. 22-23 [S. 7].), so wird auch Egger zu Beginn der Erzählung in seinen Paratexten und -bildern seine Inspirationsquellen auflisten und preisen. Wie die Theogonie wird auch Eggers `Epos` zum Artikulationsmedium von Spiritualität, philosophischer Betrachtung und Meditation. Hier wie dort dient die poetische Form »als Ausweis der Inspiriertheit« (Auerochs 2007, 643) der Texte. Val di Non präsentiert sich nicht ınurı als Literatur, sondern als Ausdruck einer besonderen sspirituellen` Haltung einer Landschaft gegenüber.

2.3. Val di Non ist ein Bilderbuch. Egger hat der Prosa und den Gedichten eine dritte `Stimme beigefügt (»stets fügt sich eine zweite Stimme zur ersten, dann noch eine, und dann noch und noch« Egger 2017, Klappentext): zarte, filigrane Bilder von sehr präziser Ausführung. Sie stammen aus der Hand des Autors selbst. Egger ist in künstlerischer Hinsicht ein Doppeltalent, eine Zweifachbegabung, er ist ein Wort- und Bildkünstler. Er schafft sich mit seinem Bild-Epos ein eigenes Genre mit eigenen ästhetischen Möglichkeiten. Val di Non ist auch ein Künstlerbuch, insofern der Autor-Illustrator hier das Objekt Buch selbst zum Thema macht. ${ }^{13}$ Die sorgfältige optische Gestaltung des Bandes betont den Zeichencharakter der Rede. Die Seiten sind zum Großteil zweigeteilt: In der oberen Hälfte des Blattes stehen Verse und Zeichnungen, in der unteren Hälfte der Prosatext. Nur selten gibt es seitenfüllende Zeichnungen oder gar doppelseitige Zeichnungen ohne Text. Für seine Illustrationen wählt Egger den graphischen Stil: Er schafft Zeichnungen aus feinen Linien (zumeist Umrisslinien), Schraffuren und Punkten. Sie sind alle in Schwarz-Weiß gehalten, sehr flächig und ohne Hintergrund. Indes, keinesfalls ordnen sie sich dem Medium Sprache unter, haben keinesfalls eine rein illustrative Funktion, sondern erzählen selbst. Der Definition von Abraham und Knopf zufolge ist das Bilderbuch

nicht eine literarische Gattung neben anderen [...]; sondern es nimmt erstens - ebenso wie man das auch für den Film sagen kann - alle drei Großgattungen der Literatur in sich auf und kann episch (narrativ), dramatisch (szenisch) und selbstverständlich auch lyrisch

13 Von der »Öffnung hin zu Formen des bildgebundenen Erzählens - bis hin zum Erzählen in Bildern« als »[e]ine[r] wichtige[n] Tendenz der zeitgenössischen Literatur «: Mit dieser Formulierung lässt sich das Künstlerbuch in seiner breiten Ausgestaltung charakterisieren (SchmitzEmans und Bachmann 2013, 11). 
sein. Und es steht, obwohl es Literatur ist, zweitens sozusagen immer mit einem Bein in einer anderen Kunst, der des Bildes [...].

(Abraham und Knopf 2014, 3)

Val di Non könnte man als szenisches Bilderbuch bezeichnen, da der Prosatext, die Verse und die Zeichnungen einer Seite jeweils eine Art Szene bilden. Vielleicht könnte man den Band auch als poetisch-fiktionales Bilderbuch definieren, in welchem die zwei literarisch-ästhetischen Modi Fantastik und Realismus miteinander verbunden werden.

Ein Bilderbuch enthält somit einen multimodalen Text, der zwei verschiedene Zeichensysteme miteinander verknüpft. Die Integration von Bild und Schrifttext auf einer "Sehfläche" führt nicht lediglich zu einer Addition der dort jeweils enthaltenen Informationen, sondern zu einer Potenzierung der semiotischen Leistung.

(Staiger 2014, 12)

Das multimodale Intervall führt zur »Anreicherung (enhancement)« (Staiger 2014, 15) sowohl des Textes als auch des Bildes. Manchmal, wenn Text und Zeichnung sehr schwer zu dechiffrieren sind, scheinen sie gar in »Widerspruch (contradiction)« (Staiger 2014, 15) zueinander zu stehen. Das zweiteilige Modell zeigt sich auch in der zweifachen Erzählinstanz: Es gibt eine verbalsprachliche Erzählinstanz mit einer (sowohl im Prosa- als auch im Lyrikteil) zumeist internen Fokalisierung (es gibt so etwas wie ein narratives und ein lyrisches Ich) und eine bildliche Erzählinstanz, die anhand `phantastischer`Zeichnungen erzählt. Es ist ein Mix aus diegetischem und mimetischem Modus.

2.4. Eggers Poetik der »Zusammenverbundenheit der Untal-Intervalle« (Egger 2017, 207) steht im Zeichen seiner Ästhetik der Coincidentia oppositorum. Im Folgenden werde ich versuchen, die Schönheit und Eleganz des Bandes als Effekt der harmonischen Gleichzeitigkeit von Gegensätzlichem zu beschreiben. Zwischen Schrift und Bild, Prosa und Lyrik, Aussage und sreiner (schöner) Form<, >Wahrheit` und `Trug` im Hesiod'schen Sinne ${ }^{14}$ (`wirklichen` und serfundenen` Wörtern) gibt es grundsätzlich ein großes Gleichgewicht. Dies macht den eigentümlich schwebenden Zustand der Erzählung aus. Es gibt keine Spannungsbögen, wie sie im realistischen Erzählmodus üblich sind, wohl aber eine anhaltende Spannung von anderer Qualität. Es ist die Intensität des Sprechens, die sich den

14 Im Prooimion der Theogonie (um 700 v. Chr.) reflektiert Hesiod das Verhältnis von >Wahrheit< und Fiktion in der Literatur. Die Musen lehrten ihm Lügen und Wahrheit: »Solche Reden vernahm ich zuerst von den göttlichen Frauen, / den olympischen Musen, den Töchtern des Herrschers der Aigis. / >Hirten auf freiem Feld, Gesindel, gierige Bäuche, / täuschend echte Lügen wissen wir viele zu sagen. / Wahres jedoch, wenn wir wollen, wissen wir gleichfalls zu künden.« (Hesiod 1991, V. 24-28) 
durchgehend offenen Intervallen verdankt. Sie zeigt sich etwa (um nur einen Aspekt unter vielen zu nennen) in der gleichzeitigen Beachtung und Aufhebung der Satzgrammatik. Die Rede ist von gleitenden Übergängen bestimmt: von der grammatikalischen Korrektheit zu Abbrüchen oder grammatikalischen `Digressionen (der Satz schwenkt in eine andere als die erwartete Richtung); von einem Erzähltempus ins andere; vom Indikativ in kaum begreifliche Konjunktive; von verständlichen, rational nachvollziehbaren Schilderungen zu surreal-phantastischen Momenten; von heute im Standarddeutschen gebräuchlichen zu längst vergessenen oder archaisch-dialektalen Wörtern, die allerdings auf `moderne` Weise flektiert oder konjugiert werden. Dramatische Beschreibungen in rhythmischer Prosa von hoher musikalischer Qualität werden von zarten, höchst undramatischen Zeichnungen begleitet. Äußerste Genauigkeit (optisch in den `präzisen Zeichnungen, verbal in den seitenfüllenden Details der Schilderungen) paart sich mit der Leere, die sich einerseits zwischen den Linien der Zeichnungen und im Weißraum des Blattes auftut, die sich andererseits `hinter` der Fülle der erzählten Details bemerkbar macht. Immer gibt es Zwischenräume; das `Ganzeく löst sich auf bzw. stellt sich als "Zusammenverbundenheit« von Materie und Nichts heraus. Zwischen den Gegensätzen öffnet sich ein Feld voller Schwingungen. Im Wechsel der Register kann Intensität entstehen als schwebende Signifikanz, nämlich als eine Art »Streuungseffekt«, durch den »Textsinn und Textbedeutung nie ganz deckungsgleich werden« (Kleinschmidt 2004, 140).

\section{Close reading des Anfangs}

Die erste Seite enthält eine Zeichnung sowie einen kursivierten Satz, das Motto: »Ich singe, also bin ich, singe ich.« (Egger 2017, 5 [o. Seitenz.]) Es steht am unteren rechten Rand des Blattes.

Das sehr zarte Bild evoziert eine fließende Bewegung. Oben rechts entspringend, sergießtı sich die Zeichnung über die ganze Seite in die untere linke Ecke. Aus dem Nichts tauchen vereinzelt winzige, kreisförmige Elemente auf (Tropfen). Sie werden dichter und vereinigen sich zu einem zusammenhängenden Ganzen: zu einem schmalen, gewundenen Bachbett, das nur aus Umrisslinien besteht. Es ist die äußerst reduzierte Darstellung einer Quelle, die zum Bach anschwillt. Dieser endet aber plötzlich in einer beutelförmigen Ausbuchtung. Der Bach verschwindet wieder im Nichts.

Der als Motto zu verstehende Satz »Ich singe, also bin ich « stellt einen klaren intertextuellen Bezug zu Descartes' berühmtem, vielfach zitiertem und variiertem Satz »Cogito ergo sum» her. Er ist, neben der Zeichnung und Eggers eigenem 


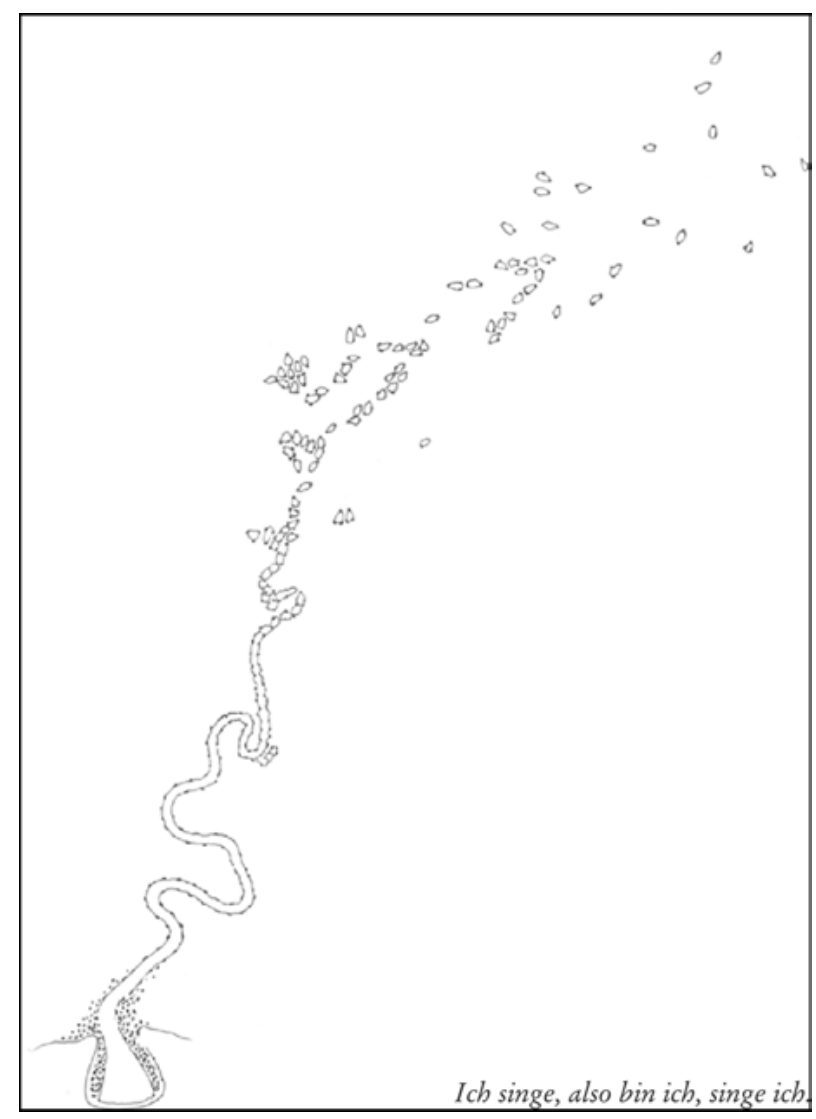

Abb. 2: Egger 2017, 5 (o. Seitenz.).

Satz, die dritte Stimme, die ihrerseits die vielen Stimmen evoziert, die Descartes' Satz aufgenommen und variiert haben.

Der Satz präsentiert sich als lyrische Erhöhung und gleichzeitig als parodistische Umkehrung des Descartes'schen Originals. Grammatikalisch gesehen, handelt es sich um eine indirekte Rede. Der Satz »Ich singe, also bin ich « ist die Aussage des singenden Subjekts (»[...] singe ich«) und verliert damit seine absolute Gültigkeit. Erst am Ende des Satzes wird deutlich, dass der erste Teil (»Ich singe, also bin ich«) durch den eigentlichen Hauptsatz (» ... singe ich«) relativiert wird. Die Pointe liegt im Überraschungseffekt dieses `Zusatzes`, der sich als das semiotisch entscheidende Element herausstellt. Der erste Teil »Ich singe, also bin ich« drückt - in Anverwandlung des kartesianischen Gedankens - das für das Ich wichtigste Argument für die Tatsächlichkeit der eigenen Existenz aus. Weil es singt, 
lebt es. Der Gesang ist das letzte, unerschütterliche Fundament (fundamentum inconcussum) seines Daseins. Doch diese Gewissheit erweist sich als >bloßer sang, der (im Sinne Hesiods) zwar wahr sein könnte, genauso gut aber auch eine ıtäuschend echte Lüger. Zwischen Wahrheit und Lüge im Gesang öffnet sich ein Intervall.

Eggers Dialog mit dem bekannten Vorbild bewirkt keinesfalls dessen einfache Umkehrung. Weder ist der Gesang das Gegenteil von Denken noch bedeutet der Zusatz (»[...] singe ich«), dass die Richtigkeit des Gesungenen geleugnet wird. Vielmehr verliert alles seine Eindeutigkeit. Alles ist Gesang, ein Mix aus Realität und Phantasie, aus Sicherheit und Zweifel. Dieses Motto entwirft für das gesamte Buch eine Fluchtlinie aus allen fixierten Bedeutungen.

Gleichzeitig könnte das Motto auch tatsächlich Descartes' Satz widerlegen. Gegen die Beschränktheit der rationalen Erkenntnis (cogito) setzt Egger die Subjektivität und Magie der Einbildungskraft. Damit stünde das Intervall zwischen Zitat und Original im Zeichen des Widerspruchs.

Auch der Sänger Hesiod besingt in der Theogonie den Ursprung der Götter und der Welt. Sein Gesang gibt wieder, was die Musen ihn gelehrt haben, also Wahrheit und Trug. Der Kunst (dem Gesang) gehe es »immer darum«, so Deleuze und Guattari, »das Chaos durch eine Schnittebene zu überwinden, die es durchquert« (Deleuze und Guattari 1996, 240). Aus der Berührung mit dem Chaos entstehen die Kinder des Chaos. Auch Hesiod ılernt` von den Musen, dass am Anfang von allem das Chaos war. Aus ihm entstanden die Erde und der Eros, der alles verbindet:

\footnotetext{
Wahrlich, als erstes ist Chaos entstanden, doch wenig nur später

Gaia, mit breiten Brüsten, aller Unsterblichen ewig sicherer Sitz, der Bewohner des schneebedeckten Olympos, dunstig Tartaros dann im Schoß der geräumigen Erde, wie auch Eros, der schönste im Kreis der unsterblichen Götter: Gliederlösend bezwingt er allen Göttern und allen Menschen den Sinn in der Brust und besonnen planendes Denken. Chaos gebar das Reich der Finsternis: Erebos und die schwarze Nacht, und diese das Himmelsblau und den hellen Tag, von Erebos schwanger, dem sie sich liebend vereinigt.
}

(Hesiod 1991, V. 116-125)

Ein genauer Blick auf den ersten Satz des Buches zeigt eine Wiederholung mit Variation. Eine Stimme beginnt aus dem Nichts zu sprechen. Dann versichert sie sich ihrer selbst: »also bin ich «, um schließlich das »Ich singe« zu wiederholen, indem sie es zugleich invertiert. Als performativer Akt gelesen, wird das Motto zu einem Ritornell, wie es Deleuze und Guattari nennen würden. Seine Funktion sei, im Chaos Ordnung zu schaffen und im Dunkeln Orientierung zu 
schenken. In ihrem gemeinsamen Werk Tausend Plateaus wird im ersten Abschnitt des Kapitels »Zum Ritornell« der Begriff erklärt:

Ein Kind, das im Dunkeln Angst bekommt, beruhigt sich, indem es singt. Im Einklang mit seinem Lied geht es weiter oder bleibt stehen. Hat es sich verlaufen, versteckt es sich, so gut es geht, hinter dem Lied, oder versucht, sich recht und schlecht an seinem kleinen Lied zu orientieren. Dieses Lied ist so etwas wie der erste Ansatz für ein stabiles und ruhiges, für ein stabilisierendes und beruhigendes Zentrum mitten im Chaos. Es kann sein, daß das Kind springt, während es singt, daß es schneller oder langsamer läuft; aber das Lied selber ist bereits ein Sprung; es springt aus dem Chaos zu einem Beginn von Ordnung im Chaos, und es läuft auch jederzeit Gefahr zu zerfallen. Der Ariadnefaden erzeugt immer Klänge.

(Deleuze und Guattari 1992a, 424)

Orientierung in der Dunkelheit bietet demnach nicht das Tasten, sondern der Gesang. Das Ritornell bietet Orientierung in der Konfusion; die Wiederholung eines Satzes beschwichtigt die Angst. Durch das >Labyrinth des Un-Tals zieht sich ein Ariadnefaden aus Klängen und Bildern. Gesponnen wird er aus der variierenden Wiederholung bestimmter Zeichnungen, Wörter und Motive. Im Ritornell wird die reine Wiederholung (der Refrain) durch Variation gebrochen. Die Lautgestalt des Mottos ist also poetisches Programm.

Im Lichte von Bachtins Ästhetik des Wortes gelesen, kündet schließlich das Motto von der >Redevielfalt $\triangleleft$ des Buches. Demnach ist der erste Satz bereits eine »hybride Konstruktion mit zwei Akzenten und zwei Stilen« (Bachtin 1979, 195). Denn in der Rede des Ichs zeigt sich eine fremde Rede: die von Descartes. Was zu einem einzigen Sprecher zu gehören scheint, umfasst »in Wirklichkeit aber zwei Äußerungen, zwei Redeweisen, zwei Stile, zwei `Sprachen`, zwei Horizonte von Sinn und Wertung « (Bachtin 1979, 195). Val di Non spiegelt die Redevielfalt einer reellen Landschaft ebenso wie die des Wortkünstlers und Viellesers Oswald Egger.

Wenn nun das Bild und der Satz ein multimodales Intervall bilden - worin besteht dann das Gemeinsame, das sie verbindet? Sie künden vom Ursprung des fließenden Gewässers wie vom Fluss des Gesangs. Aus dem Nichts steigen fluide Partikel auf, die zu einem rauschenden Ganzen anschwellen, um wieder im Nichts zu verschwinden.

Seite 6: Auf der ansonsten leeren Seite steht zentral am oberen Rand des Blattes ein Zitat: " ... - nichts, nichts, nichts, nichts, nichts, nichts, und auf dem Berge nichts. Juan de la Cruz« (Egger 2017, 6 [o. Seitenz.]). Die Worte stammen aus dem Buch Aufstieg auf den Berg Karmel des spanischen Mystikers und Dichters Johannes vom Kreuz (eigentlich Juan de Yepes y Alvares, 1542-1591). In der deutschsprachigen Ausgabe des Werkes findet sich zu Beginn die deutsche Fassung jener Zeichnung, die Johannes vom Kreuz für Magdalena del Espíritu Santo zur Illustration des Aufstiegs angefertigt hat (Johannes vom Kreuz 1999, 42). In der 


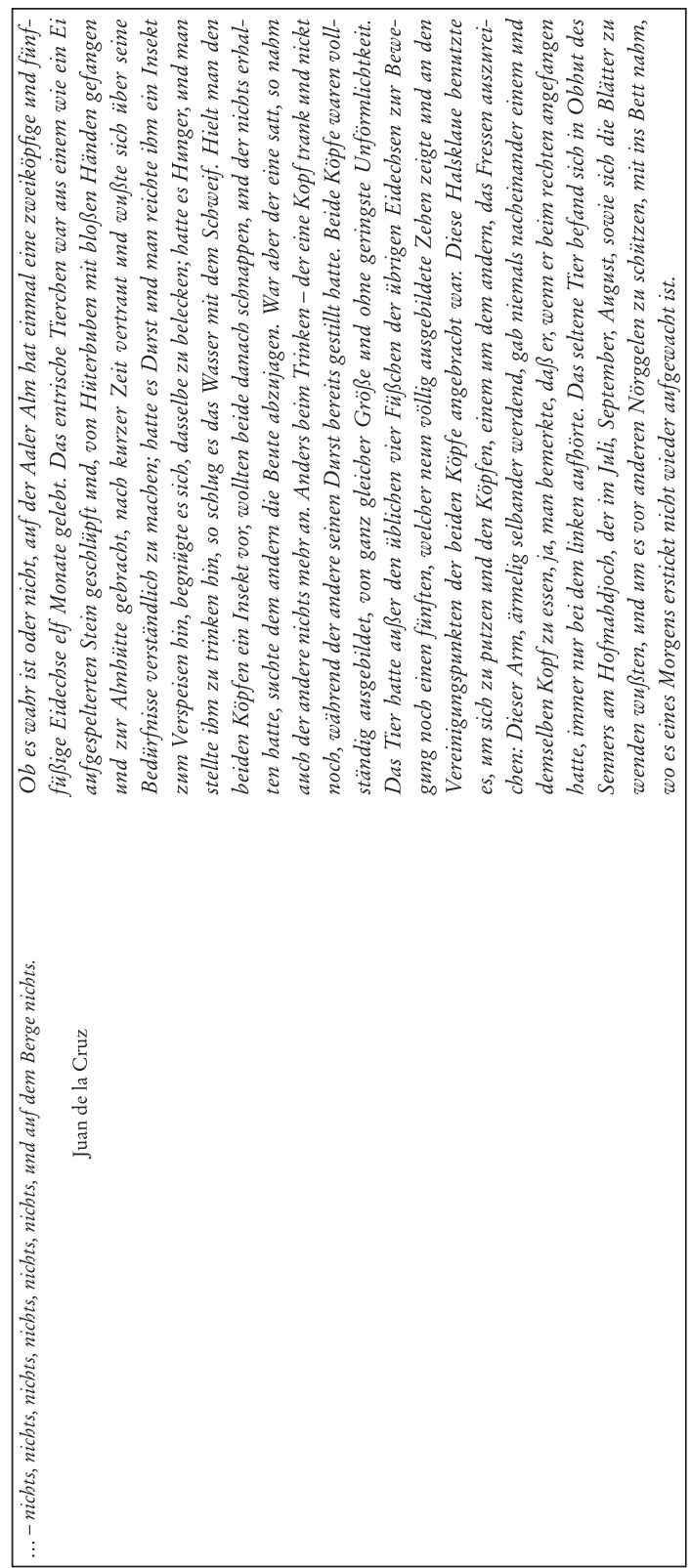

Abb. 3: Egger 2017, 6-7 (o. Seitenz.). 
Mitte ragt ein stilisierter (nur durch Umrisslinien angedeuteter), sehr schmaler und steiler Berg in die Höhe. In ihm stehen, in vertikaler Anordnung, von unten nach oben verlaufend, die Worte: »Pfad auf den Berg Karmel - Geist der Vollkommenheit nichts nichts nichts nichts nichts nichts und auf dem Berg: nichts«. Oberhalb des Berges stehen die Worte: »Auf diesem Berg wohnt nur Gottes Ehre und Ruhm.« Es ist das umfangreichste Werk des großen Mystikers, der zugleich zu den größten Dichtern in spanischer Sprache zählt. In ihm beschreibt Johannes den geistlichen Weg zur unio mystica, der Liebesvereinigung mit Gott. Er beschreibt ihn als Aufstieg der Seele aus dunkler Nacht zum Herrn. Schritt für Schritt soll das Buch den Gottsuchenden aus der Gefangenschaft seiner Wünsche und vorgefertigten Meinungen zu vollkommener innerer Freiheit führen, die ihn offen macht für die Erfahrung Gottes.

Der zweite Paratext führt also die Stimme der Mystik in den Introitus ein. Obwohl hier ausschließlich die Stimme des spanischen Mystikers aus dem sechzehnten Jahrhundert zu ertönen scheint, sieht eine intertextuell orientierte Lektüre auch hier eine »hybride Konstruktion mit zwei Akzenten und zwei Stilen« (Bachtin 1979, 195). In der Rede des Johannes versteckt sich diejenige des Autors Egger: Wie der Berg Karmel für Johannes, so wird der Nonsberg für Egger zum Bild eines Aufstiegs, an dessen Ziel das Nichts steht. Die Texte und Zeichnungen werden zu Etappen (Schritten) auf dem Weg in eine immer tiefere Kontemplation. Das Untal ist die Vision eines Suchenden. Die Schrecknisse und Schönheiten des Untals, die der Wanderer erfährt, befreien ihn Schritt für Schritt von der Beschränktheit der Perzeptionen und Affekte und öffnen sein Herz für >das Ganzeく.

Das Nichts kann in Eggers Werk als Ritornell bezeichnet werden, welches alle seine Bücher verbindet. Es wird immer wieder beschworen. Es scheint tatsächlich eine stabilisierende Funktion zu haben. Nur wenige Beispiele seien hier erwähnt:

Nichts, das ist, 2001 erschienen, trägt den Untertitel »Gedichte«, aber der Band besteht formal aus mehreren Ebenen, nicht nur aus Gedichten: Auch hier sind die Seiten zweigeteilt, auch hier zieht sich durch die oberen Hälften der Seiten ein lyrisches Narrativ, durch die unteren Hälften das Prosa-Narrativ, begleitet von filigranen Zeichnungen. Oberhalb beider Ebenen jedoch, gewissermaßen als durchgehender langer Kolumnentitel und durch eine Trennungslinie vom übrigen Textkorpus gesondert, zieht sich in Großbuchstaben ein Text, der mit folgenden Worten beginnt: »ES GIBT NICHTS (DAS ES NICHT GIBT) UND NICHTS, DAS IST UND, ZU ZWEIEN, UNEINS, DAS EINE X (MAL) + DAS ANDERE [...]« (Egger 2001, 6f.)

Der Klappentext zu Nichts, das ist lautet:

Wo viele Wörter sind, ist viel Stille. Als wäre das Gedicht, die »Welt in der Welt«, eingefriedet und umschrieben von einer Mauer beständig ineins fallender Gegensätze. Und die 
können sich immer und überall ereignen [...]. Der Ort bleibt im Gedicht, mitgedacht, während die Zeit in der Erzählung vergeht. Auch die Alpen, wo noch Residuen voreuropäischer Substratsprachen wurzeln, bergen Nichts, das ist.

(Egger 2001, Klappentext)

2007 erschien nihilum album, das mit »Weißes Nichts« übersetzt werden könnte (wobei das Substantiv nihilum ein Archaismus ist, aus dem sich das klassische nihil entwickelt hat) und das den Untertitel »Lieder \& Gedichte« trägt. Die vielen Vierzeiler knüpfen ein Netz aus Bildern und Klängen, die in der Fülle der Details "alles« einfangen. Zwischen und `hinter den Versen ertönt die Stille, die sich einstellt, wenn alle Gegensätze in eins fallen. Sie ist die unio mystica des Dichters. Sie ist dem weißen Licht vergleichbar, das alle Farben enthält. In Versen wie

\author{
Nichts \\ hat sich verändert, \\ nichts bewegt sich \\ die ganze Zeit.
}

(Egger 2007, 71)

wird die Stille des absoluten Still-Stands hörbar. Die Verse scheinen mit dem Glück einer wiedergefundenen Stille auf die verlorene (tosende) Stille von John Cage $^{15} \mathrm{zu}$ antworten.

Im Berg des zweiten Paratextes versteckt sich im Sinne Bachtins auch Hesiods Helikon, der heilige Berg der Musen. Doch die Bewegung der Inspiration ist invertiert: Während in der Theogonie die Musen vom heiligen Berg herabsteigen und dem Schafe hütenden Hesiod den Dichterstab in die Hand drücken, handelt es sich hier um einen Aufstieg, besser Aufschwung, der Schritt für Schritt vollzogen wird.

Schließlich verbirgt sich im Nichts des zweiten Paratextes auch Jean Pauls berühmte »Rede des toten Christus vom Weltgebäude herab, dass kein Gott sei« (Jean Paul SW I/2, 270-275) und öffnet als negatives nihilistisches Nichts ein Intervall zum positiven mystischen Nichts. Wiewohl bei Jean Paul die Rede in einen Traum gebettet ist, aus dem am Ende das erzählende Ich erwacht und voller Freude feststellt, dass alles nur ein Traum war und es wieder glauben darf (»Meine Seele weinte vor Freude, daß sie wieder Gott anbeten konnte ... «; Jean Paul SW I/2, 275), so mindert dieses Happy End doch keineswegs die im Alptraum

15 Der Komponist und Dichter John Cage bereicherte die Musik durch den Zufall und den Humor, durch die Stille, die Geräusche des Alltags, die liebende Hinwendung zu den rabsichtslosen` Geräuschen der Welt. Im Jahr 1978 führte er gemeinsam mit Tito Gotti das PerformanceStück Der Zug. Auf der Suche nach der verlorenen Zeit auf (Cage und Gotti 2008). Dieses Stück inspirierte Friederike Mayröcker zu ihrem Gedicht "sauf der Suche nach der verlorenen Stille، (John Cage)« (Mayröcker 1993, 116-117). 
ausgedrückte tiefe existenzielle Angst, dass in der Höhe nichts sei, dass die Welt ein kaltes, starres Nichts sei:

Ich lag einmal an einem Sommerabende vor der Sonne auf einem Berge und entschlief. Da träumte mir, ich erwachte auf dem Gottesacker. [...] Jetzo sank eine hohe edle Gestalt mit einem unvergänglichen Schmerz aus der Höhe auf den Altar hernieder, und alle Toten riefen: „Christus! ist kein Gott?«

Er antwortete: »Es ist keiner.« [...]

Und als Christus das reibende Gedränge der Welten [...] sah [...]: so hob er, groß wie der höchste Endliche die Augen empor gegen das Nichts und gegen die leere Unermeßlichkeit und sagte: "Starres, stummes Nichts! Kalte, ewige Notwendigkeit! Wahnsinniger Zufall! [...] Wie ist Jeder so allein in der weiten Leichengruft des All! （Jean Paul SW I/2, 272-274)

In diesem Text vollführe Jean Paul ein Gedankenexperiment, indem er nihilistische Positionen ausprobiere, so Monika Schmitz-Emans (2015). Die »humoristische Stilmischung« (Müller 1983, 250) im Siebenkäs, der Wechsel vom Lächerlichen ins Schrecklich-Erhabene, bei welchem sich das Lächerliche nur als Kehrseite des Erhabenen herausstellt, erinnert an Eggers Ästhetik der in eins fallenden Gegensätze. Jean Pauls Witz und Tiefsinn sind die stets präsenten Folien, vor denen Eggers Kunst der paradoxen Zusammenführungen zu lesen sind.

Seite 7: Der dritte Paratext ist eine kurze Erzählung, in der Tirolisches Sagengut um geologische Phänomene und um die Magie der Einbildungskraft erweitert wird: Auf der Aaler Alm (am Nonsberg) schlüpft eine zweiköpfige und fünffüßige Eidechse aus einem Stein, wird von Hüterbuben gefunden und zu einem Senner gebracht. Zwischen den beiden Köpfen hat das Tierchen noch ein fünftes Füßchen mit neun Zehen, das den zwei Köpfen das Essen reicht. Um es zu schützen, nimmt es der Senner in sein Bett, wo es erstickt.

Eine Inhaltsangabe erfasst bei Egger nie das Wesentliche. Die im Ton einer mündlichen Volkssage erzählte kleine Geschichte vereint das Wissen um geologisch interessante Funde mit einer poetologischen Reflexion.

Das Gampenjoch (1518 m) ist der niederste Übergang vom Raum Burggrafenamt zum Nonsberg. Über ihn führt seit Jahrtausenden ein alter Weg, der für die Menschen Saum- und Pilgerweg sowie Salzstraße in einem war (Gampenpasskomitee 2015). Über ihn erreichten sie den alten Wallfahrtsort Unsere Liebe Frau im Walde, wo es seit dem zwölften Jahrhundert ein kleines Kloster gibt, das der Jungfrau Maria geweiht ist. Die heutige Passstraße, in den 1930er Jahren erbaut, ist ein Bravourstück der Straßenbauingenieurskunst. Entlang ihrer Strecke genießt man nicht nur herrliche Ausblicke ins Tal und auf die umliegenden Berge, sondern erkennt verschiedenste Felsprofile, die durch den Bau der Gampenstraße erschlossen wurden. Unterhalb der Passhöhe wurden 1996 vom Geologen Marco Avanzini 235 Millionen alte Reptilienspuren gefunden. Es war eine geologische 
Sensation. Vergleichbar alte Spuren gibt es weltweit nur noch in den USA und in Kanada, so der Geologe Patrik Ausserer (2015, 210). Am bergseitigen Straßenhang sind die Gesteinsschichten »eine vollständige Abfolge Voltagokonglomerat« (ebd.). Diese Schichten werden, so Ausserer, in Küstennähe abgelagert (ebd.). Sie zeugen von einem prähistorischen (nun steinernen) Meer, welches sich hier befunden haben muss. Die meisten steinernen Reptilienspuren serzählen vom Rhynchosauroides tirolicus, einem eidechsenähnlichen Tierchen, welches eine Länge von bis zu 60-70 Zentimetern erreichen konnte (ebd.). Er war ein Vorfahre der uns bekannten Dinosaurier und, so Ausserer, den heutigen Leguanen ähnlich. Die Füßchen im Gestein zeigen dünne Finger, die mit Krallen besetzt waren. Sie erinnern in ihrer Feingliedrigkeit an eine menschliche Hand (ebd.). - In der Felsgeburt der zweiköpfigen und fünffüßigen Eidechse versteckt sich demnach die Stimme des Nonsbergs selbst, der hier aus seiner eigenen Urgeschichte erzählt.

Eine weitere intertextuelle Stimme könnte der Kult des Mithras sein, des persischen Gottes des Lichts, welcher der Sage nach einem Felsen entsprang. Zeugen seiner Felsgeburt waren steinzeitliche Hirten (Vermaseren 1951). Die Verehrung des Mithras war ein Mysterienkult, der sich, etwa zeitgleich mit dem Christentum, im ersten Jahrhundert nach Christus im ganzen römischen Reich verbreitete. Auch im Alpenraum zeugen zahlreiche archäologische Funde von der Beliebtheit dieses Gottes.

Zwischen der Felsgeburt der Egger'schen Eidechse, den steinernen Reptilienspuren am Gampenpass, der Geburt des Mithras und der `Geburt ` des Novellabaches am oberen Nonsberg öffnen sich Intervalle. Verbunden werden sie durch die Vorstellung einer petra genetrix (Vermaseren 1951, 290), welche Leben zeugt.

Es gibt zahlreiche alpenländische Volkssagen, in denen Eidechsen auftauchen. In den meisten Fällen sind sie gutmütig und tun dem Menschen nichts. Eine Sage aus Vorarlberg erzählt gar von einer Eidechse, die einem guten, tierliebenden Mann das Leben rettet (Vonbun 1950, 82). Auch in einer Sage aus dem Südtiroler Passeiertal (»Der Übelsee bei Stuls«) sendet die Muttergottes eine Eidechse aus, um einen Hirten zu retten (Menghin 1884, 51-53). Im Gebiet von Rovereto südlich von Trient liebt man die Eidechse als Freundin und Beschützerin der Menschen. Wenn sich eine Viper dem Menschen nähert, lenkt die Eidechse sie ab, indem sie deren Aufmerksamkeit auf sich selbst zieht (Dalla Torre 1894, 27).

Der aus Meran gebürtige Germanist und Volkskundler Vinzenz Ignaz Zingerle (1825-1892) sammelte gemeinsam mit seinem Bruder (dem Vorbild der Brüder Grimm folgend) Sagen aus Tirol (Zingerle 1850). In seiner umfangreichen Sammlung findet sich allerdings auch eine Sage aus Villanders (Südtirol), in der mehrköpfige Eidechsen auftauchen: Als ein Knabe eine Eidechse tötet, taucht eine zweite mit zwei Köpfen auf, dann eine dritte mit drei Köpfen und so fort, bis schließlich eine Eidechse mit sieben Köpfen sich im Kopf des Knaben verbeißt, 
der am Ende nur durch eine List gerettet werden kann. Eidechsen sind, so der Volksglaube, dämonische (numinose) Kräfte, die dem Menschen beistehen, solange er sie achtet, die sich aber verteidigen, wenn ihnen Leid zugefügt wird. Laut Lorelies Ortner stehen im Mittelpunkt von dämonologischen Sagen »jenseitige Gestalten«. Sie »konfrontieren den Menschen mit dem Numinosen« (Ortner 1997, 42).

Eggers >Sage` (Egger 2017, 7 [o. Seitenz.]) beginnt mit einer Wendung, die auf eine mündliche Überlieferung hinweist: »Ob es wahr ist oder nicht ... « Ein unvollständiger indirekter Fragesatz als Einleitung impliziert, vergleichbar dem »Es war einmal ... « der Märchen, dass nicht Wahrheit das Kriterium für die folgende Erzählung ist. Der Sprecher präsentiert sich als Nachkomme des Schafe hütenden Hesiods, der ja auch, noch vor der eigentlichen Erzählung, die zweifache Qualität seiner Rede hervorhebt: Wahrheit und täuschend echte Lüge, beides ein Geschenk der Musen. Nicht um Wahres zu sagen, hauchen ihm die Musen die göttliche Stimme ein, sondern um Schönes zu singen.

[...] auf der Aaler Alm hat einmal eine zweiköpfige und fünffüßige Eidechse elf Monate gelebt. Das entrische Tierchen war aus einem wie ein Ei aufgespelterten Stein geschlüpft und, von Hüterbuben mit bloßen Händen gefangen und zur Almhütte gebracht, nach kurzer Zeit vertraut und wußte sich über seine Bedürfnisse verständlich zu machen [...]

(Egger 2017, 7 [o. Seitenz.])

»Entrisch« ist ein altes, noch heute in Tirol gebräuchliches Wort. $\mathrm{Zu}$ »enterisch« sagt das Grimm-Wörterbuch: »insolitus, mirus, monstruosus, unheimlich, ungeheuer, ein nur in Baiern, Österreich und Schlesien fortlebendes, in der Schweiz, in Schwaben nicht vorkommendes wort.« (DWB 3, Sp. 512) ${ }^{16}$

Das Wort »aufgespeltert« ist im heutigen Standarddeutsch nicht existent, doch findet man im Grimm-Wörterbuch das feminine Substantiv »spelte: f. abgespaltenes stück« (DWB 16, Sp. 2140). Egger hat das Verb »aufspeltern« im Sinne von »aufspalten« analog dazu geschaffen. Dieses alt-neue Wort evoziert das Bild eines Steins, dessen Schale sich öffnet, spaltet, auftut.

Das Tierchen weiß seine Bedürfnisse kundzutun: Es ist ein kluges und eigenwilliges Wesen. Beim Essen scheinen die Köpfe denselben Hunger zu verspüren; sie sind beide satt, sobald einer sich satt gegessen hat. Beim Trinken hingegen haben die Köpfe verschiedene Bedürfnisse. »Beide Köpfe waren vollständig ausgebildet, von ganz gleicher Größe und ohne geringste Unförmlichkeit." (Egger 2017, 7 [o. Seitenz.]) Hier fällt das Wort »Unförmlichkeit« anstelle des zu erwartenden »Unförmigkeit« auf. Laut Duden kann »unförmlich« die veraltete Form für »unförmig« mit der Bedeutung "plump, ungestalt« sein. In diesem

16 Das Deutsche Wörterbuch [Grimm-Wörterbuch] wird im Folgenden unter der Sigle DWB mit Angabe der Bandnummer zitiert. 
Sinne sind die zwei Köpfe der Eidechse von schöner, edler Gestalt. Andererseits: Das Grimm-Wörterbuch definiert »förmlichkeit« als »ritus, caerimonia« (DWB 3, Sp. 1902). In diesem Licht gesehen wird »ohne geringste Unförmlichkeit« zu einem weit offenen Bedeutungsintervall. Es geht nicht um die Form der Köpfe, sondern um ihre Fähigkeit, (sprachliche, poetische?) Formen zu wahren.

In Dalla Torres Die volkstümlichen Thiernamen in Tirol und Vorarlberg findet man unter dem Eintrag »Eidechse«, dass eine Tirolische Variante dafür auch »Egerechs" ist und aus dem Althochdeutschen »egidëhsâ« stammt (Dalla Torre 1894, 27). Egerechs aber klingt fast wie Egger-Echs, Egger-(Ei)dechse. Zwischen dem entrischen Tierchen und dem Autor selbst öffnet sich ein Intervall. Eggers Witz (wie der seines `Vorfahren ` Jean Paul) findet im Gleichklang (Homonymie) von Wörtern neue Zusammenhänge. Es lohnt sich, diesen eigentümlichen Sprung nachzuvollziehen. Dann wären also die zwei Köpfe der Egerechs die zwei künstlerischen Modi des Autors-Illustrators oder die zwei Modi der verbalen Erzählung (Prosa und Lyrik) oder aber die zwei Dimensionen des `Musengeschenks` (Wahrheit und täuschend echte Lüge, Fakt und Fiktion), Wirklichkeit und Traum, Tal und Untal oder aber einfach die zwei Sprachen des Oswald Egger (das Tirolische des Nonsberg und das sogenannte >richtige` Standarddeutsch). Dann könnte von den neun Zehen des fünften Füßchens, das den zwei Köpfen das Essen reicht, ein Bogen zu den neun Musen geschlagen werden. Und die Egerechs mit ihren zwei Köpfen an nur einem Rumpf wird zum Symbol für alle in eins fallenden Gegensätze.

Vom fünften Füßchen heißt es wenig später:

Dieser Arm, ärmelig selbander werdend, gab niemals nacheinander einem und demselben Kopf zu essen, ja, man bemerkte, daß er, wenn er beim rechten angefangen hatte, immer nur bei dem linken aufhörte.

(Egger 2017, 7 [o. Seitenz.])

Auch das Wort sselbander ist ein Egger-Ritornell, das sich durch alle seine Texte zieht. Im Grimm-Wörterbuch findet man es unter dem Eintrag "selb«: »selbander wird nicht selten als prädicat verwendet, als gegensatz zu allein, einsam« (DWB 16, Sp. 424). Der fünfte Arm (plötzlich ein Arm!) wird sich selbst ein anderer. Er ist nicht mehr eine mit sich idente Einheit, sondern eine in sich differente Einheit. Dies erinnert an Deleuze' Konzept der Differenz, wie er es in Differenz und Wiederholung entwickelt (Deleuze 1992b): Wir müssen Differenz als Differenz in sich denken, da eine reine Differenz nicht im Verhältnis zu einer Identität definiert werden kann (im Sinne von Nicht-X) oder nach Maßgabe der Differenz zwischen zwei Identitäten (etwa der Differenz zwischen $\mathrm{X}$ und $\mathrm{Y}$ ). Vielmehr ist Differenz als Möglichkeit zu denken, als virtueller Unterschied, welcher als Potenzial zwischen sich selbst stets verändernden Identitäten besteht. Die reine Differenz ist als in einem steten Werden begriffene Variation von Ver- 
hältnissen zu denken, so wie auch Identität sich in einem steten Prozess des Werdens befindet. $^{17}$

In diesem Sinne kann ıselbander` bei Egger als zentraler Begriff seiner Ästhetik der in eins fallenden Gegensätze verstanden werden: Alles, sowohl die Dinge als auch die Wahrnehmungen und Empfindungen, ist in einem fortwährenden Prozess der Veränderung, der Entwicklung, der Ent-Faltung begriffen. Wenn sich die Dinge selbander werden, werden sie intensiv. Das, was zunächst fest und einförmig erscheint, wird bei aufmerksamer (poetischer, spiritueller) Betrachtung heterogen. Die Eidechse wird zu einem Schauspiel unendlicher Differenzen. In dieser Erfahrung einer sich steigernden Differenz der Phänomene offenbart sich laut Deleuze für das betrachtende Ich die >Intensitätı der Dinge. Jede Intensität sei nämlich differentiell. Sie ergebe sich aus einer Ungleichheit, welche wiederum auf andere Ungleichheiten verweise: „Da sie [die Intensität] das Ungleiche an sich enthält und bereits Differenz an sich ist, bejaht die Intensität die Differenz. Sie macht aus der Differenz einen Gegenstand von Bejahung.« (Deleuze 1992b, 296)

Der fünfte Arm der Eidechse wird sich »ärmelig selbander«. ২Ärmelig` taucht im Grimm-Wörterbuch nicht auf. Das Suffix -ig dient der Adjektivbildung. Wird sich der Arm selbst zur Hülle (Ärmel), die den Arm umgibt, so wie in der Poesie die Imagination die reinen Fakten umhüllt?

Das seltene Tier befand sich in Obhut des Senners am Hofmahdjoch, der im Juli, September, August, sowie sich die Blätter zu wenden wußten, und um es vor anderen Nörggelen zu schützen, mit ins Bett nahm, wo es eines Morgens erstickt nicht wieder aufgewacht ist.

(Egger 2017, 7 [o. Seitenz.])

Das »Nörggele« ist die Deminutivform von »Norg« (mask.), welches seinerseits vermutlich aus dem italienischen orco (< lat. Orcus) entlehnt wurde. Eine Variante ist »Lorg « (Ortner 1997, 46), welches als Verdeutschung des italienischen »l'orco« zu erkennen ist (der italienische Artikel wurde als solcher nicht mehr erkannt). Norg ist aus »ån (ein) Org« entstanden (im Laufe der Zeit wurde auch der deutsche Artikel als solcher nicht mehr erkannt). ${ }^{18}$ Ein Nörggele ist in der Tiroler Sagenwelt ein »freundlich gesinnter (nützlicher) oder bösartiger (schädlicher) Zwerg, Wichtelmännchen« (Ortner 1997, 47). Im Grimm-Wörterbuch findet

17 Diese brillante Zusammenfassung des komplexen Begriffs Differenz bei Deleuze übernehme ich nahezu wörtlich aus James Williams 2012, 37 (meine Übersetzung).

18 Diese sprachgeschichtlich hochinteressanten Erklärungen sowie viele Hinweise zu den Mundarten und der Landschaft des Nonsbergs verdanke ich dem Sprachwissenschaftler und gebürtigen Nonsberger Cristian Kollmann. 
man unter dem Eintrag »Norke«: »nork, norg, m. was orke, tirol. ein spukmännchen, wicht [...] ZINGERLE sagen 39f. 42f. 53. 55 (fem. die nörgin, deminutiv der und das nörgel, das nörkelein, nörglein); in Defereggen der norgge, etwas verkrüppeltes, und das nerggile, eine kleine unansehnliche person [...] «. (DWB 13, Sp. 899) Das Nörggele entstammt dem Orcus, der `Unterwelt` des Nonsbergs und der Sprache, und kehrt dorthin auch wieder zurück.

Die Eidechse und der Senner fassen schnell Vertrauen zueinander, ja der Senner will das Tierchen vor anderen Nörggelen schützen und nimmt es in bester Absicht zu sich ins Bett. Doch: Wer ist hier eigentlich das Nörggele? (Das Wort taucht in der Erzählung an dieser Stelle erstmals auf.) Nörggelen sind in den Tiroler Sagen in aller Regeln nicht selbst Bauern oder Senner, sondern tauchen plötzlich auf einem Hof auf und verdingen sich als Knechte, wo sie viel Unfug treiben und mit Vorliebe die Mägde necken. Dass hier, in Eggers `Sage`, der Senner das Nörggele ist, ist nur eine (eher unwahrscheinliche) Lesart. Eine andere Lesart würde in der Eidechse (Eger-echs) selbst das (eigenwillige, neckische) Nörggele sehen, welches vor anderen geschützt werden muss (es würde sich hier um einen selbstreferenziellen Egger'schen Witz handeln). Damit würde sich das Intervall hin zu anderen schreibenden Echsen (etwa Kritiker-Echsen) öffnen, die der Egger-Echse nicht wohlgesonnen sind. Der Tod der Eidechse am Ende kann als freiwillige Rückkehr ins Nichts gelesen werden oder aber als Folge einer zwar wohlmeinenden, aber erstickenden Fürsorge. Beim Senner, der Verkörperung der Konformität, geht der Eger-(Egger-)echs die Luft aus.

Die Invertierung der Ordnung im Satz »im Juli, September, August, sowie die Blätter sich zu wenden wußten« (auch ein Ritornell bei Egger) kann als Einspruch gegen die Linearität der Zeit und als poetologische Metapher gedeutet werden: Das Phänomen Nörggele kommt und geht mit dem Umblättern der Seiten, welche nicht nur linear (im Sinne einer üblichen Ordnung), sondern auch von hinten nach vorne oder in zirkulären Bewegungen gelesen werden können.

Seite 9: Hier stehen zwei Zeichnungen mit einer Legende. Im Rahmen des mehrseitigen >Paranarrativs übernimmt nun das Bildnarrativ das Wort.

Die linke Zeichnung zeigt einen flachen, ringförmigen, zylindrischen Körper mit einer kleinen zentralen Öffnung. Sie erinnert an eine Erdöffnung, den antiken Omphalos, den Nabel der Welt. Von der Öffnung ausgehend ziehen sich strahlenförmig lauter Linien über den gesamten Körper, sodass er als Ganzes einem verschnürten Beutel aus plissiertem Stoff ähnelt. Es ist eine Seeanemone, ein wirbelloses, an einen festen Ort in der Tiefe des Meeres gebundenes Tier. Ein altes, heute in der Zoologie nicht mehr gebräuchliches Wort für Lebewesen an der Grenze zwischen Pflanze und Tier ist »Zoophyt«, weitere Beispiele für Zoophyta sind Schwämme und Korallen. Diese Zeichnung ist eine der vielen 


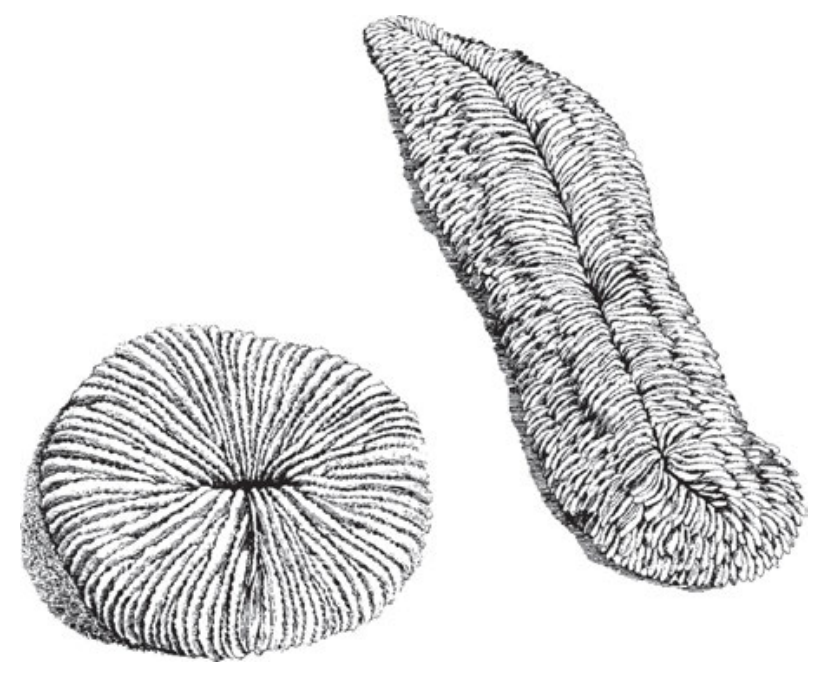

Nonsberger Störungsbündel (Tethys vagina)

Abb. 4: Egger 2017, 9 (o. Seitenz.).

Darstellungen von Zoophyten, von Ur-Lebewesen im ganzen Buch. Die Seiten wimmeln nur so von Protozoa, von Ein- oder Zweizellern, die vage an Kopffüßler mit Augen, Mund und Nase erinnern, sowie von Seenesseln.

Die rechte Zeichnung ähnelt der linken, doch sind hier Körper und Öffnung in die Länge gezogen. Grasähnliche `Haare` bedecken den schlauchförmigen Körper. Er wirkt elastisch und lebendig. Er erinnert (gleichzeitig) an ein schmales Tal (aus der Vogelperspektive gesehen), an eine schmale Felsöffnung und an eine Vagina.

Unter den beiden Zeichnungen steht: »Nonsberger Störungsbündel (Tethys vagina)« (Egger 2017, 9 [o. Seitenz.]). Der Inhalt von Klammern hat in einem Prosatext zumeist eine erklärende Funktion. »Tethys vagina « also als Erklärung von »Nonsberger Störungsbündel«? Innerhalb der Bildlegende kündigt sich bereits ein Intervall an.

Aus geologischer Sicht verlaufen über den Nonsberg mehrere sogenannte Störungen. »Störung « bedeutet in der Geologie eine

Dislokation, [d. h. eine] tektonische oder atektonische Unterbrechung oder Veränderung des primären Gesteinsverbandes an Fugen, Brüchen, Klüften oder Verwerfungen oder aber auch weiträumige bruchlose Verbiegungen (Falten, Flexuren, Monoklinen). ([N. N.], »Störung«)

Die »Hauptstörungslinie« (Ausserer 2015, 206), die sogenannte Periadriatische Naht, zieht sich in Südwest-Nordost-Richtung über das Hofmahdjoch bis in die Nähe von Meran. Sie trennt das Südalpin vom Ostalpin. Hier verläuft, so Ausse- 
rer, geologisch gesprochen, die »Grenze zwischen Afrika und Europa» (ebd.). Beinahe parallel zur Periadriatischen Naht verläuft die Völlaner Linie, welche »die Sedimente von den Vulkaniten des Laugen trennt« (ebd.). (Der Laugen ist ein hoher Gebirgskamm, welcher den Nonsberg im Norden vom Ultental trennt.) »Im Bereich des Gampenpasses trennt sich die Völlaner Linie zu mehreren fast parallelen Störungsflächen, welche das umliegende Gestein stark deformieren.« (ebd.)

Als Störungsbündel (im Sinne von mehrfachen Veränderungen oder Brüchen) können aber auch die Mundartgrenzen bezeichnet werden, die über den Nonsberg verlaufen. Eine erste Mundartgrenze zieht sich westlich von Meran von Norden nach Süden: Sie trennt Zentraltirol von Randtirol (zu welchem man das Nonsberg-Gebiet und das Ultental sowie, weiter nördlich, das Ötztal zählt). In den Mundarten dieser jahrhundertelang sehr abgelegenen Gebiete haben sich »einige markante konservative Merkmale bewahrt (Schwienbacher 1997, 36). Eine zweite Grenze, die zwischen dem deutschsprachigen und dem italienisch- bzw. rätoromanischen Sprachraum, verläuft südlich der deutschsprachigen Gemeinden Laurein, Proveis und Unsere Liebe Frau Im Walde-St. Felix. Diese bis heute sehr klare Sprachgrenze besteht seit vielen Jahrhunderten und ist durch Urkunden belegt. $^{19}$

Das (linke) Bild des Bündels aus plissiertem (stark gefaltetem) Stoff >zeigt also die Bündelung der über den Nonsberg verlaufenden Störungen, während das rechte Bild gewissermaßen die Nahaufnahme einer einzigen Störungslinie (der Periadriatischen Naht) zeigt. Aus einer Öffnung im Gestein, welche durch Verschiebungen entstanden ist, entspringt eine Quelle: die Novella (der Bach) und die Novelle (Erzählung) von Val di Non.

»Tethys vagina« ist einerseits der Name eines tonnenförmigen, transparenten Meerestieres, dessen Innenorgane sichtbar sind. Der Name wurde ihm 1802 vom deutschen Naturforscher, Arzt, Zeichner und Kupferstecher Wilhelm Gottlieb Tilesius von Tilenau gegeben (vgl. [N. N.], »Thetys vagina«). Andererseits evoziert der Begriff die Titanin Tethys, Tochter des Uranos (Himmel) und der Gaia (Erde) und Mutter aller Frischwasserquellen. Sie war die Gemahlin von Okeanos, dem Gott aller Meere, dem sie unzählige Flüsse und Meeresnymphen, die Okeaniden, gebar. Unter ihren Söhnen, den Flüssen, befinden sich bedeutende Ströme wie der Nil und der Istros (Donau):

19 Kollmann 2012, 25: „Die germanisch-romanische Sprachgrenze am Nonsberg scheint nach Ausweis der Überlieferung und Mundartforschung von Anfang an sehr fest gewesen zu sein. Naturgemäß kam es hie und da zu Mischehen in beide Richtungen, aber diese haben sich auf die Sprachgrenze nicht und auf die Sprache selbst kaum ausgewirkt.« Siehe auch Gampenpasskomitee 2015, 146-151, inbes. 148. 


\begin{abstract}
Thethys aber gebar dem Okeanos wirbelnde Flüsse:
Neilos, Alpheios, Eridaanos, tief von Wirbeln durchzogen,

Strymon, Maiandros, Istros mit herrlich wogender Strömung,

Phasis, Rhesos, Acheloos, glänzend von silbernen Wirbeln.
\end{abstract}

(Hesiod 1991, V. 337-340)

In den Zeichnungen öffnen sich mehrfache Intervalle. Viele Linien werden gebündelt (und werden zu >Plateaus` im Deleuz'schen Sinne, d. h. zu Bündelungen von Fluchtlinien): die geologische und die sprachliche Ebene, der antike Mythos und die poetologische Rede. Die Geburt aller Flüsse und Bäche verdankt sich Eros, der Tethys mit Okeanos in Liebe verband. Ohne Eros gäbe es keine Gewässer, so wie es keine fließende Rede gäbe ohne den `erotischen Blickı des Dichters, welcher sich den reellen und imaginierten Phänomenen liebevoll zuneigt, Gegensätzliches heranzoomt und vereinigt.

Eggers Val di Non ist, bildlich gesprochen, ein weitverzweigtes System an Wasserwegen: Unzählige Quellen werden zu wirbelnden Bächen, welche in Hauptströme münden, deren zahllose Nebenarme ihrerseits durch ein hochkomplexes Kanalsystem verbunden sind. Eggers poetische Wasserlandschaft ist ein einziges, großes Netz, in welchem alles mit allem verbunden ist. So verbindet ein (unterirdischer) ১Kanal Seite 9 (Tethys vagina, petra genetrix) mit den Seiten 200-201. Auch sie stehen im Zeichen des Bildnarrativs: Das Bild, welches zwei Seiten füllt, zeigt merkwürdige Gestalten, welche an Tiere aus der Urzeit erinnern (Protozoa, Ur-Reptilien, Ur-Amphibien, Ur-Hirsche und einen Seeigel). Die Tiere umringen eine aufrecht stehende Frauengestalt mit gefalteten Händen. Ihre rund gebogenen Arme und gefalteten Hände bilden zusammen eine stilisierte Gebärmutter. Auch ihre geöffneten, leicht gebogenen Beine bilden eine ovalförmige Öffnung, die an eine Vagina erinnert. Unter dem Ensemble steht die Legende »Unsere liebe Frau im Walde (Anbetungen der Bärmutter)« (Egger 2017, 200 [o. Seitenz.]). Wieder fällt die Klammerkonstruktion auf, welche die Worte innerhalb der Klammer mit denen außerhalb in ein explizierendes bzw. ergänzendes Verhältnis setzt. Die christliche Gottesmutter des alten Nonsberger Wallfahrtsorts und die alte europäische (vorindogermanische) Muttergöttin, die oft als bärengestaltige Göttin der Geburt verehrt wurde, verweisen aufeinander. Es ist zu vermuten, dass das kleine christliche Kloster (welches zugleich auch ein Hospiz für Pilger war) an der Stelle eines Heiligtums errichtet wurde, in welchem diese alte Muttergottheit verehrt worden war. Die (Ge-)Bärgöttin symbolisierte den Anfang und das Ende. Die Menschen hatten den jährlichen Rückzug der Bären in einen todesähnlichen Winterschlaf und ihre Wiederkehr aus dem >Reich des Todes` beobachtet und als göttliche Erscheinungen gedeutet. Die Bärin wurde zum Symbol für den Neuanfang. Als Göttin war sie es, die in der Geburt Leben schenkte. Sie war es auch, die über das Sterben des alten 
Jahres wachte und als Lichtbringerin mitten im Dunkeln das neue Jahr gebar. ${ }^{20}$ Zwischen Tethys, der Viel-Gebärenden, zu Beginn von Val di Non und der Bärgöttin am Ende des Buches spannt sich der Bogen der Novella-Novelle. Das Leben (auch das imaginierte) und das Wasser stehen in einer engen Beziehung.

Der letzte Paratext vor dem eigentlichen Beginn der (Novelle-)Erzählung ist sehr rätselhaft:

Es erhob sich eine gelbe Wolke, und gelber Regen fällt nieder und blieb liegen. Der Regen hat einen gelben Fisch mitgebracht, was die gelben Schäfer gesehen haben. Sie sind ohne Füße herbeigelaufen, den Fisch haben sie ohne Hände gefangen, ohne Messer aufgeschnitten, ohne Salz gesalzen, ohne Feuer gebraten, ohne Mund gegessen.

(Egger 2017, 10 [o. Seitenz.])

Er erinnert an das berühmte Volksrätsel »Vogel federlos«, welches erstmalig auf Latein in einer Reichenauer Handschrift auftaucht und vermutlich aus dem frühen zehnten Jahrhundert stammt. ${ }^{21}$ Seit der frühen Neuzeit finden sich davon viele volkssprachliche Versionen:

flog Vogel federlos, sass auf Baum blattlos,

kam Frau fusslos, fing ihn handlos,

briet ihn feuerlos, frass ihn mundlos. ${ }^{22}$

Die Lösung dieses alten Rätsels (der Schnee) ist bekannt. Ganz anders das >Rätsel zu Beginn von Val di Non. Es bieten sich drei Möglichkeiten an, mit ihm umzugehen.

a) Man geht möglichst vielen der unzähligen Bedeutungsmöglichkeiten nach, die vom Rätsel in alle nur erdenkbaren Richtungen ausstrahlen: etwa dem Tierregen als meteorologischem Phänomen, dem Fisch als astrologischem Zeichen, dem Fisch in der christologischen Deutung (Christus-Fisch, dessen Leib von den Gläubigen gegessen wird); man erforscht den Symbolcharakter der Farbe Gelb; man interpretiert den gelben Regen als chemische Waffe, als Bienenschwarm oder gelben Bienenkot etc. Vermutlich käme man an kein Ende.

b) Man liest das Rätsel als Chiffre für Eggers Poetik der in eins fallenden Gegensätze: Der Text (das Ganze) besteht aus lauter Paradoxa (»ohne Füße herbeigelaufen [...] ohne Hände gefangen [...] ohne Messer aufgeschnitten [...] ohne

20 Zur alt-europäischen Muttergottheit in Bärengestalt Gimbutas 2001, insbes. 36-37.

21 Der lat. Originaltext: »Volavit volucer sine plumis, sedit in arbore sine foliis, venit homo sine manibus, conscendit illum sine pedibus, assavit illum sine igno, et comedit illum sine ore.« Siehe Tomasek 1994, 119-122.

22 Die an altgermanische Stabreimverse angelehnte Übersetzung stammt von Heusler (19221923, 109). 


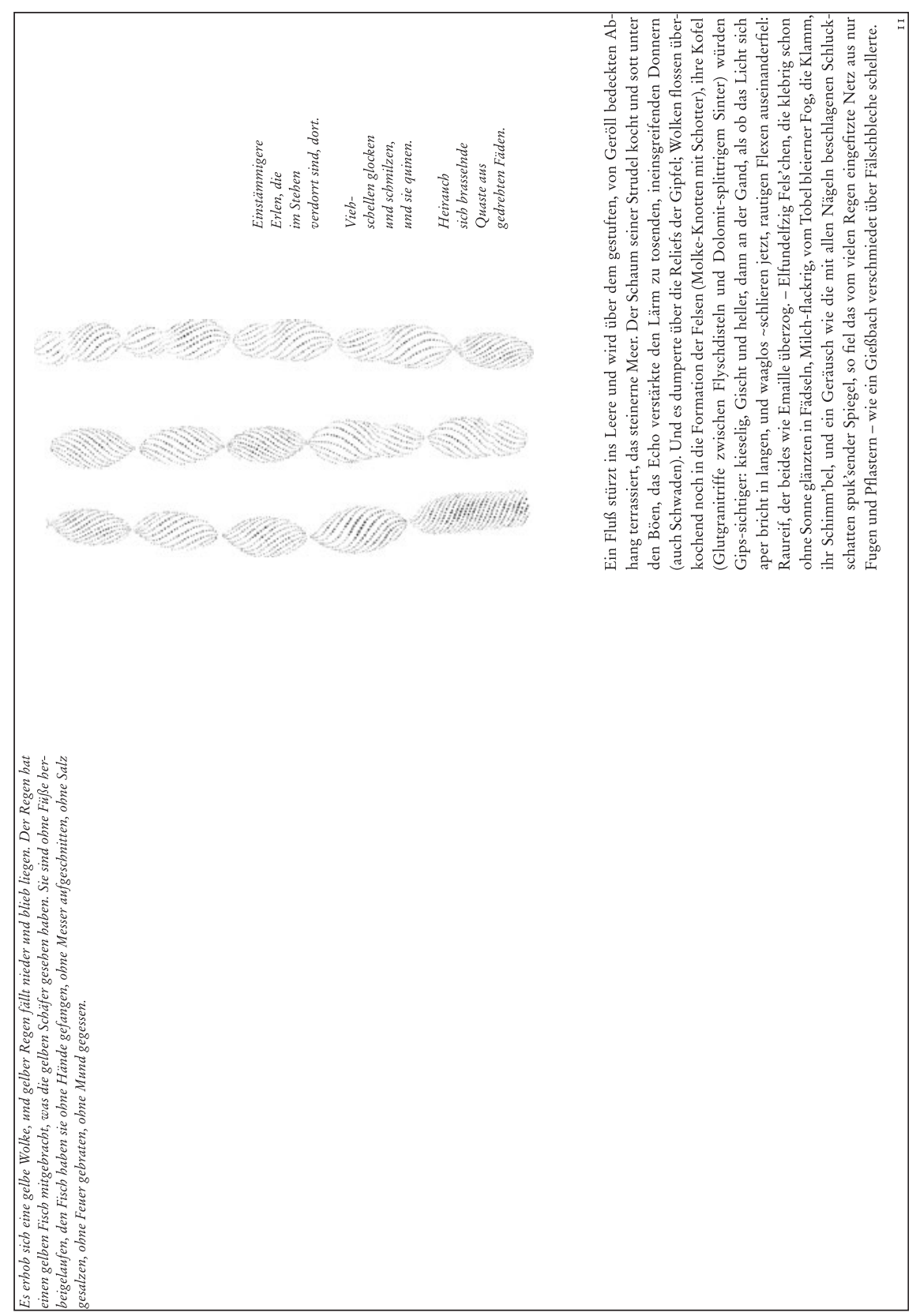

Abb. 5: Egger 2017, 10 (o. Seitenz.)-11. 
Salz gesalzen [...] ohne Feuer gebraten [...] ohne Mund gegessen.«). Auch der vielfache Wechsel des Erzähltempus (vom Präteritum zum Präsens ins Perfekt etc.) entspräche dann der ıganzen` poetischen Zeit, die im Buch erzählt wird.

c) Man liest den Text als ein Koan und macht es zum Instrument einer (poetischen) Meditation. Koans sind kurze, mit dem logischen Verstand nicht aufzulösende Texte, die im Zen-Buddhismus von den Meistern den (jungen) Mönchen als Aufgabe gegeben werden (etwa: Was ist das Geräusch einer einzelnen klatschenden Hand?). Diese besteht darin, das logisch-dichotome Denken zu überwinden und zur persönlichen Einsicht zu gelangen. An den Aussagen der Schüler erkennt der Meister, ob er auf dem Weg zur Erleuchtung Fortschritte macht. Koans sollen den Geist des Meditierenden beruhigen, indem sie ihn füllen, bis dessen Innenwände vom Koan widerhallen. Dieses Echo (es ist immer ein sehr individuelles) ist die >Antwort ‘ des Meditierenden. Sie stellt sich nur ein, sobald der Meditierende die Beschränktheit seines Bewusstseins erkennt und akzeptiert.

In the view of the Chán Buddhists, discursive thinking based on the principle of binary opposition creates by itself binary relationships, fragmenting the whole into parts and counterposing them to one another. As a result, the unity and holism of being is destroyed, and a person begins to alienate himself from his inner nature, counterposing his individual ego to all objective reality, which begins to be perceived as an external, objectbased reality. ${ }^{23}$

Demnach würde sich in den Paradoxa des Textes die Fragmentierung der Welt widerspiegeln, die durch den logischen, trennenden Verstand verursacht wird. Sie wird im Text als Ganzem aufgehoben.

Das Paradoxon »ist häufig in manieristischer und religiöser, insbes. mystischer Literatur anzutreffen - dort als Element des ästhetischen Spiels, hier als Verklausulierung rational nicht zugänglicher Glaubensinhalte«, so das Metzler Literatur Lexikon (Moennighoff 2010, 568). Eggers aus Paradoxa bestehendes Rätsel erlaubt, ja verlangt nach beiden Lesarten: als Spiel und als mystischer Text gelesen zu werden.

Auf dieser Seite beginnt das seigentliche` dreifache Narrativ: Ein 13-zeiliger Prosatext auf der unteren Seitenhälfte beschreibt den obersten Verlauf des Novella-Baches. Die obere Seitenhälfte teilen sich eine Zeichnung (bestehend aus drei horizontalen, aus vielen Fäden gedrehten Kordeln) und ein Gedicht (bestehend aus drei Vierzeilern).

23 Suprun u. a. 2013, 50. Siehe auch Matsuyama 2018. 
Diese binäre Seitenstruktur wird im ganzen Buch beibehalten (mit Ausnahme jener Seiten, die ganz mit Zeichnungen gefüllt sind): Oberhalb eines 13-zeiligen Prosatexts stehen Zeichnungen und Verse.

Der erste Satz beginnt mit der Wucht des stürzenden Wassers:

Ein Fluß stürzt ins Leere und wird über dem gestuften, von Geröll bedeckten Abhang terrassiert, das steinerne Meer.

(Egger 2017, 11)

In der Nähe von St. Felix am oberen Nonsberg stürzt die noch junge Novella in eine tiefe, sehr schöne Schlucht, weshalb der Bach in der deutschen Mundart auch Tieftalbach genannt wird. ${ }^{24}$ Wer oben steht, sieht durch die Gischt nicht auf den Grund des brodelnden Kessels, sodass das Wasser im tiefen Schlund zu verschwinden scheint. Auch gibt es Durchgänge im Felsen, sodass man von hinten die tosende Wasserwand betrachten kann, die in den Abgrund stürzt. Tatsächlich prägen mehrfache Terrassierungen das Bild des Val di Non. Die Gewässer Novella und Noce fließen über Stufen Richtung Süden. Funde von steinernen Muscheln und Meerestieren zeugen vom einstigen Meer (»das steinerne Meer«).

Im zweiten Satz fallen die Zeiten »ineins«; er beginnt im Präsens und fährt im Präteritum fort:

Der Schaum seiner Strudel kocht und sott unter den Böen, das Echo verstärkte den Lärm zu tosenden, ineinsgreifenden Donnern (auch Schwaden).

(Egger 2017, 11)

»[U]nd sott unter den Böen«: Hier wechselt das Tempus und auch das Szenario. Die Jetztzeit des Wasserfalls mit seinem kochenden Kessel (»Der Schaum seiner Strudel kocht«) wechselt unmittelbar in »unvordenklich[e]« (Egger 2017, 207) Zeiten, als Stürme das Meer zum Sieden brachten. Dann schwenkt die Kamera (allerdings unter Beibehaltung des Präteritums) zurück in die Schlucht, da es ein Echo nur zwischen Felswänden geben kann: »das Echo verstärkte den Lärm zu tosenden, ineinsgreifenden Donnern (auch Schwaden)« (Egger 2017, 11). Die Bilder schieben sich ineinander. Die Schlucht fällt mit dem Urzeit-Meer in eins. >In eins ist ein zentraler Begriff in Eggers Poetik der unendlichen coincidentiae oppositorum. Bilder einer in sich differenten Einheit folgen aufeinander. Der Lärm und sein vielfaches Echo sind zeitlich versetzte akustische Phänomene, die aber als Ganzes zusammengehören. In der Vervielfachung wird die Stimme des Wassers gewaltig und schrecklich (Lärm, tosende Donner) und also erhaben.

Es folgt eine Beschreibung der terrassenförmigen Gesteinsformationen, über die das Wasser fällt. Beachtenswert sind in Eggers Texten die vielen Nuancierun-

24 Für diesen Hinweis danke ich Cristian Kollmann. 
gen, etwa »Donner (auch Schwaden)«. Schwaden (Nebelschwaden, feinster Wasserstaub) sind ein optisches Phänomen, welches hier der Erklärung eines akustischen Phänomens (des Donners) dient. Der synästhetische Effekt ergibt sich wiederum aus einem Bild, in welchem zwei differente Effekte auf denselben Grund zurückzuführen sind. Die Nuance steht im Dienste der Genauigkeit; sie dient der Erkenntnis der Wahrheit. Die Wahrheit liegt nicht in der objektivierenden und abstrahierenden wissenschaftlichen Klassifikation; vielmehr liegt sie im Besonderen, im einzigartigen Phänomen, im unwiederholbaren Augenblick, für den sich die Kunst interessiert. ${ }^{25}$ Das Buch Val di Non setzt sich aus unwiederholbaren Augenblicken zusammen, die die sauseinandergefaltete $Z_{\text {Zit }}{ }^{26}$ wieder zusammenführen.

Und es dumperte über die Reliefs der Gipfel; Wolken flossen überkochend noch in die Formation der Felsen (Molke-Knotten mit Schotter), ihre Kofel (Glutgranitriffe zwischen Flyschdisteln und Dolomit-splittrigem Sinter) würden Gips-sichtiger: kieselig, Gischt und heller, dann an der Gand, als ob das Licht sich aper bricht in langen, und waaglos schlieren jetzt, rautigen Flexen auseinanderfiel: Raureif, der beides wie Emaille überzog.

(Egger 2017, 11)

Im Folgenden können nur einzelne, ausgesuchte Sprachphänomene erwähnt werden, die die besondere Klanggestalt dieses Textes ausmachen.

Egger hebt Wörter aus tiefen (archaisch-dialektalen) Sprachschichten an die Klangoberfläche und >veredeltı sie durch Pfropfen (Suffixe, Infixe) in Richtung Standard-Deutsch, hier etwa »dumperte«, »Knotten«, »Kofel« und später »Schimm'bel«.

$\mathrm{Zu}$ dumperte sagt das Wörterbuch der Südtiroler Mundarten: »dumper, dimper [mhd. timber, timmer (= finster, dunkel, trüb, dumpf)]: 1. dämmrig, dunkel: `Es wird scho glei dumper, es wird scho glei Nåcht ... <(Weihnachtslied) 2. dumpf, benommen« (Moser 2015, 59). Die Verbalbildung dumpern steht hier für ein dumpfes Grollen.

25 Lange 2005, 15: »Wo der Sinn für und die Lust an der Nuance um sich greift, da rückt das Abseitige und Flüchtige in den Blick, das Ephemere, für die Vernunft Unfaßbare. [...] Als ein Kunstgriff und eine Denkfigur, die sich dem Einzigartigen verschrieben hat, übt die Nuance Verrat an dem, was Nietzsche als das auszeichnende Merkmal des griechischen Geschmacks ansah: an der Vorliebe für das Typische und Generelle. Das Akzidentielle und bloß Kontingente überwuchert das Essentielle und Notwendige, das Künstliche erhebt sich über das, was als Natur absolute Geltung beansprucht, der Schein triumphiert über das Sein, das Jonglieren mit Nuancen und Details sowie die Entfaltung unscheinbarster Differenzen substituiert, was Kunst und Literatur einst bewegte, der Wille, im Kleinen ein Bild vom großen Ganzen zu geben.«

26 Egger 2017, 207: »Das arela Areal, welches [...] die ganze Zeit - ineinanderschneidtelnd auf blätterte $[. .$.$] .«$ 
Knotte bedeutet auf Tirolerisch: »Knotte, Knott, Knottn, der [mhd. Knote (= Knoten)]: Fels, großer Steinbrocken, kleiner Hügel.« Wenn also milchigweiße Wolken in Felsen überfließen, entstehen »Molke-Knotten«. (Moser 2015, 160)

Kofel schließlich bedeutet: »[mhd. Kofel (= Bergspitze): weitere Herkunft unklar]: Bergkuppe, Felsblock]« (Moser 2015, 161). Die Granitspitzen der Berge (Kofel) werden im Meer der Wolken zu Glutgranitriffen. Glutgranit, ein Neologismus, evoziert flüssigen Granit, welcher als Glutstein (Magma) aus dem Erdinneren an die Erdoberfläche trat. Granit zählt zu den Plutoniten. Diese entstanden, als sich das Magma noch innerhalb der Erdkruste langsam abkühlte (vgl. [N. N.], »Magma«).

Das Wort Flysch hat der Geologe Bernhard Studer 1827 dem lokalen Dialekt des Schweizer Simmenthals im Berner Oberland entnommen und in die geologische Terminologie eingeführt. Es bezeichnet dort »ein schieferiges, mergeliges, plättchenförmiges spaltbares, leicht verwitterbares Gestein« (Früh 1903-1905, 218). Etymologisch steht es in Verbindung mit dem altnordischen flaz (= flach, engl. flat) und bedeutet `Ebene, Schieferebene`. Flysch wird für jene Stellen an Gehängen verwendet, wo Erdreich und Schutt abrutschen, wo also eine Entblößung stattgefunden hat. Während der Entstehung der Gebirge (die sich über Millionen von Jahren hingezogen hat) sind immer wieder Gesteinsschichten über den Hang des Kontinentalschelfs in die Tiefsee abgerutscht, sodass "marine Sedimentabfolgen« entstanden (vgl. [N. N.], »Flysch«). Flysch besteht abwechselnd aus Schichten von harten Tonschichten (aus sehr langsamen Ablagerungsprozessen) und feinkörnigeren Schichten von Schuttmaterial (das schnell gerutscht ist). Flysch bezeichnet also marine Ablagerungen, die sich während der Gebirgsfaltungen aufgefaltet und verschoben haben. In der Bedeutung von sfließendem Gestein evoziert Flysch hier eine bewegte Landschaft, die ihr Gesicht im Laufe von Jahrmillionen mehrfach geändert hat. Der Nonsberg spiegelt den »Wechsel zwischen Prozessen der Erosion und der Sedimentation wider, welche zum Teil vor und während der letzten Eiszeit vor etwa 115.000 bis 10.000 Jahren stattfanden." (Ausserer 2015, 206) Er ist Teil des adriatisch-ionischen Flyschs.

Was aber sind Flyschdisteln? Geologisch können distale und proximale Fazies unterschieden werden. Bei distalem Flysch sind die ıschnell fließenden Geröllschichten (Turbidite) eher dünn (dünne Siltbänder), während im proximalen Flysch oft auch $1 \mathrm{~m}$ hohe Sandsteinbänke enthalten sein können. Egger macht aus distalem Flysch Flyschdisteln. Zwischen dem geologischen Terminus und der Blume (Distel) entsteht ein Klangintervall, welches das Bild steinerner Blumen evoziert.

Und wie ist der auffällige und merkwürdige Konjunktiv II und wie der Komparativ in »ihre Kofel [...] würden Gips-sichtiger: kieselig, Gischt und heller [...]« (Egger 2017, 11, Unterstreichung EDF) zu verstehen? Der Konjunktiv ist der Modus der Vorstellung. Er kann im Deutschen (wie im Lateinischen) »das Vorgestellte als ein 
Gegenwärtiges, als ein Vergangenes und als ein Zukünftiges ausdrücken.« (Kühner 1878, 131) In diesem Sinne könnte er hier als »Konjunktiv der unentschiedenen Möglichkeit« (ebd.) gelesen werden. D. h., das Ausgesagte »wird als ein Mögliches gesetzt, gleichviel, ob dasselbe in der Wirklichkeit stattfinde oder nicht, ob die Verwirklichung desselben möglich sei oder nicht. Man pflegt den so gebrauchten Konjunktiv als Coniunctivus potentialis zu nennen«. (Kühner 1878, 131f.)

Den Komparativen fehlt hier jeweils das zweite Glied des Vergleichs. Es könnte sich um absolute Komparative handeln, die keine Steigerung signalisieren, sondern - im Gegenteil - eine »abschwächende, mindernde, einschränkende Bedeutung « (Duden Grammatik 1995, 295) haben. ${ }^{27}$ Auch dazu gibt es ein Äquivalent in den historischen >Sedimenten` der Sprache: Im Altgriechischen etwa steht häufig der Komparativ ohne das zweite Glied des Vergleichs

[...] und scheint oft nach unserer Betrachtungsweise jede Beziehung einer Steigerung verloren zu haben; aber der Grieche wurde auch hier von einem sehr feinen Gefühle geleitet. Indem er in seinem Geist irgend ein bestimmtes, durch ein natürliches Gefühl gegebenes Mass der einer Person oder Sache zukommenden Eigenschaft anschaute, so bediente er sich jedesmal der Komparativform, wenn er die an dem Gegenstand haftende Eigenschaft als in irgendeinem Grade jenes Mass überschreitend erkannte. Diese Vergleichung, die er nach dem in seinem Innern liegenden Massstabe anwandte, war ihm so ganz natürlich geworden, dass es ihm überflüssig schien, das gedachte, oft wohl nur dunkel gefühlte Mass in der Sprache auszudrücken. Der Komparativ wird daher von den Griechen da angewendet, wo wir uns der Adverbien zu, allzu in Verbindung mit dem Positive [!] bedienen, so oft irgend ein allgemeiner Gedanke, wie: als es gewöhnlich ist, als es sich schickt, billig, geziemend, recht ist und dergl., dem Redeenden klarer oder dunkler vorschwebte [...]. ${ }^{28} \quad$ (Kühner 1904, 305)

Wie aber ist Gips-sichtig? Im Grimm-Wörterbuch findet man »sichtig« als Adjektiv in der Bedeutung von »sichtbar, deutlich sehend « (DWB 16, Sp. 747). Im Althochdeutschen war es nur in der Zusammensetzung ga-, ge-, kesihtîg, ungesihtig gebräuchlich. Im Mittelhochdeutschen war es noch als sihtec, sihtic, sihtig gebräuchlich. Im Neuhochdeutschen war es laut Grimm in älterer Zeit noch ganz geläufig, später ausgestorben. Als Simplex taucht es laut dem im DWB-Artikel zitierten >Adelung، nur noch im Oberdeutschen auf, doch gehört es auch hier nur der älteren Sprache an (ebd.).

১Übersetzt` könnte der Satz vielleicht lauten: a) im Sinne eines Potentialis der Vergangenheit: Die Kofel mochten wohl, von der Helligkeit der milchig-weißen Wolken erfasst, wie Gips selbst sichtbarer geworden sein (als gewöhnlich); b) im Sinne eines Potentialis der Gegenwart: Die Kofel könnten (jetzt wie damals), von der Helligkeit der Wolken erfasst, wie Gips selbst sichtbarer werden

27 Für diesen Hinweis danke ich Emmanuel Heman.

28 Für diesen Hinweis danke ich Lav Šubarić. 
(als gewöhnlich). Der `unbegreifliche`, weil un-eindeutige Konjunktiv II würden in dieser Lesart das Einst und das Jetzt verbinden. Im Sinne eines absoluten Komparativs könnten die Kofel aber auch weniger sichtbar sein als Gips; sie könnten - wie Kiesel in der milchig-weißen Gischt der Wolken - auch weniger hell sein als sonst oder als andere Kofel.

Elfundelfzig Fels'chen, die klebrig schon ohne Sonne glänzten in Fädseln, Milch-flackrig, vom Tobel bleierner Fog, die Klamm, ihr Schimm'bel, und ein Geräusch wie die mit allen Nägeln beschlagenen Schluckschatten spuk'sender Spiegel, so fiel das vom vielen Regen eingefitzte Netz aus nur Fugen und Pflastern - wie ein Gießbach verschmiedet über Fälschbleche schellerte.

(Egger 2017, 11)

Es ist unmöglich, auf alle sprachlichen Besonderheiten dieser Zeilen hinzuweisen. Unerwähnt müssen Wörter wie »Gand «, »kieselig «, »elfundelfzig« oder »eingefitzt« bleiben. Als `Klangwolke` rezipiert, entfaltet dieser Satz das Rauschen und Toben einer Klamm; hörbar werden die Spitzen, Brüche und Fugen der Felsen und das »Schellern « (schallende Brechen) des Gießbaches.

Hingewiesen werden soll lediglich noch auf das apostrophartige »' " in manchen Wörtern wie »Fels'chen«, »Schim'bel«, »spuk'send». Es markiert ein kaum merkliches Innehalten, ein Zaudern. Es markiert einen Zwischenraum, in dem sich Tatsächliches und nur Mögliches näherkommen. Im Zaudern, sagt Joseph Vogl (2014, 15), würden gegenläufige Prozesse wirksam. Es sei ein »Intervall«, das sich auftue, wenn gegenstrebige Kräfte zusammenstoßen (Vogl 2014, 17). Als dem Deutschen unbekanntes Infix öffnet das »'« die Wörter sowohl hin zu ihrer Vergangenheit als auch hin zu ihren poetischen Möglichkeiten. ${ }^{29}$ Ein winzig kleines diakritisches Zeichen würde demnach für die Zusammenverbundenheit der Untal-Intervalle stehen.

Oberhalb des Prosatextes, welcher die Gesteinsformationen und das tosende Wasser beschreibt, stehen das Gedicht und die Zeichnung. Sie stehen für die Pflanzen, die Tiere und die Klänge, die über der Erde und oberhalb der Schlucht stehen. Diese Zweiteilung des Narrativs in >oberhalb und sunterhalb zieht sich durch die gesamte Novella-Erzählung. Immer besteht der Prosateil aus 13 Zeilen, immer nehmen also die untere und die obere Sphäre gleich viel Raum ein und bilden gemeinsam ein Ganzes. Prosa, Lyrik und Zeichnungen sind bei Egger durchaus auch das Ergebnis optischer Überlegungen.

29 Schimm'bel ist an das Tirolische Schimpl angelehnt, welches Schimmel bedeutet und sich aus dem althochdeutschen scimpalon (schimmeln) entwickelt hat und wegen der weißen Oberfläche mit »scheinen« verwandt ist (Moser 2015, 259). 
Jeder Vierzeiler besteht aus einem Satz bzw. aus einem satzähnlichen Gebilde mit abschließendem Punkt. Jeder präsentiert ein in sich geschlossenes Bild. Zwischen ihnen atmet das Gedicht.

\author{
Einstämmigere \\ Erlen, die \\ im Stehen \\ verdorrt sind, dort. \\ Vieh- \\ schellen glocken \\ und schmilzen, \\ und sie quinen. \\ Heirauch \\ sich brasselnde \\ Quaste aus \\ gedrehten Fäden. (Egger 2017, 11)
}

Es spricht eine unpersönliche lyrische Instanz. Das erste Bild zeigt verdorrte Erlen (hohe Schwarzerlen bedecken den gesamten Nonsberg). Der ungewöhnliche Komparativ (wieder ohne zweites Glied des Vergleichs) könnte als »zu einstämmig" gelesen werden. Als gedanklicher Fortsatz bietet sich an »als dass sie eine lebendige, d.h. in sich differente, Einheit bilden könnten«. Ihre szu große، Einstämmigkeit ließ keinen Spielraum für Leben, hielt sie in sich selbst gefangen, ließ sie verdorren.

Der zweite Vierzeiler bringt im Klang der Kuhglocken das Bild weidender Kühe und mit ihm die Sphäre der Landwirtschaft. Mit dem Eingriff der Menschen in die Natur verändert sich die Stimmung. Die vordergründige Idylle wird durch "schmilzen « und »quinen « empfindlich gestört. Während es das Verbum "glocken« tatsächlich als seltene Ableitung des Substantivs Glocke gibt (DWB 8, Sp. 169), könnte das nicht belegte "schmilzen« die durch die Singularform »schmilzt « `kontaminierteく Pluralform von schmelzen sein. Die Viehschellen verlieren ihre feste Form, werden flüssig, verflüchtigen sich vielleicht. "Quinen «, so das Grimm-Wörterbuch, bedeutet »kränkelnd klagen, seufzen« (DWB 13, Sp. 2370). Unter den vielen Sinnmöglichkeiten, die in alle Richtungen deuten, sei hier diejenige ausgewählt, die die Perspektive der Tiere einnimmt. Das Leben von Kühen, an deren Hälsen tagaus tagein, jahrelang, große, schwere Glocken hängen, die bei der geringsten Bewegung mit dröhnendem Lärm das feine Gehör der Tiere quälen, ist nicht idyllisch. Die übergroßen Euter hängen schwer an ihnen und behindern sie bei jedem Schritt. Ihr Leben steht im Dienst der Milchund Fleischproduktion der Menschen. Das Label "glückliche Kühe« ist aus einer einseitig menschlichen Perspektive geprägt worden. Zwischen »schmilzen« und 
Soll, was der Fall sein kann, falsch sein? Kein Valeur, also verneint davon? Das areale Areal, welches mein Tempe-, Kidron-, Licenza- und Kampanertal lustriert, istert, vom Cañon der Novella durchschlitzt, Bruchlinie und "Null leiter « einer voralpiden Gebirgsfaltung, woraus die ganze Zeit - ineinanderschneidtelnd - auf blätterte und so ungegenständig auseinanderfall'zt: mit Schalt-Intervallen, worin aber das Ganze und seine Teile auseinandertalen: Zwölf interim offene Intervall-Kapitel, durchrätselt von 365 lautgewordenen Gedanken (in Form von Worten und in Formen ohne Worte), ausge stanzt, durchsetzt davon: gehaltene, geflüsterte und ungesungen verbundene Wort-für-Wort Folgen voralpiner Substrate (keine Quellen), unvordenklich, und verbündelnd, vielfingrig ge stimmt, tektonisch geschotet, mit abschellernden Splittern und Knicksern in Störungsbün delungen oder »Felsgeburten« durch gläserne Grenzen und Komplemente, deren Existier widrigkeit, Unlinien und Unfugen dazwischen man nicht Heischen kann: »Ich habe meinen Weg, wo keiner mir voranging, selbst gebahnt, allein, und unentwegt, ginge ich durch Nichts, das ist, - ins Leere." (Horaz, Ep. I, I9) Denn "Buch« meint hier: den dritten Magen der Wiederkäner, auch Psalter, Löser, Kalender, Blättermagen, Hundertkammer, Mannigfalter - sie übersetzen das griechische echina (Igel) in Tausende Plateaus (frz. millet, fenillet, le livre) und den omasus in die Kautelen-Klaue der Ekelworte. (J. C. Peyer, De Ruminantibus et Ruminatione, 1685, siehe Seiten 88-89). Das heißt, nicht der Berg kreißt, aber das Tal wird halbiert und, in zwei Teile geteilt, durchschritten, ausgeschlachtet, verlippt, es "psaltert « fast, eine rumorendere Ausgeburt an wortwörtlich einschneidenden Unbegebenheiten, die durch den Magen gehen; Wort für Wort (als Zwickmühle) grummelte im zähglühenden Substrat der rätischen Rest- und Trümmersprache: mit morphosyntaktisch glosenden Besonderheiten und selten verstandenen Konjunktiven und Aktionsarten, Kasus und infixen Tempus- und Aspektwechseln einer eben höheren deutschen Sprache, die hier am weitesten entwickelt, qua si aufgedeutscht erscheint: im offenen Buch ruminant aufgeblättert, ein room of rumor. - Das Val di Non selbst zeichnet dieses Störungsbündel innerhalb des areallinguistischen Dial ektkontinuums vor, dessen Konnexität und Kontingenz vom Krimgotischen bis zum illy rischen, dolomitischen Fächer reicht und ununterredend und-verbunden, instantan zutage tritt: Als als Tobel, der sich selber selbstlaut schluckt, wie diese Rumpeldipumpel-Ptyx-zer burzelten Orks und Stilze durch ein Loch in einem Loch (ganz kugelig geformte, peristal tische Ungestalten): Die so lauter gewordenen Sätze springen, wie Kieselchen über das Wass er pitscheln, so wie man »im Fluß (selbstvergessen) von Klippe zu Klippe allein nur hüpfen kann, weil einer nie über die Quelle selber - unvordenklich - springt, wenn er nach denkt darüber, aber schon davon in den Bach fällt. - D.h., alle Abbildungen wurden für die ses Buch gezeichnet; und manche gehen auf illustre Instanzen zurück, wie: Louis Agassiz (Felsengeburt, Wurmverknäuelung), John Ellis (Madreporaria, Similaun) oder die Mechanik der Sedimentbewegung im Fließrinnengefüge stehender Gewässer, Anastomosen, so wie ein ganzer Auftrieb von Protozoa (Dinoflagellates, Ciliata, Crinoidea, Peridineae) durch Georges Deflandre, Geza Entz, Alfred Giard, Charles A. Kofoid, Vilém Dušan Lambl). - Die Illustra tionen lustrieren quasi, vom Lumen des Buchs aus, durch und als Ösen mosaizierende Intarsi en aneinander, die man lesen kann, in Bildern, wie diesem: "Willst du das Seiende erkennen, so gebrauche nicht deine Augen, die nur sehen, was vor den Augen ist, sondern schaue ebenso die entfernten Dinge mit dem Geist, dem sie fest gegenwärtig sind.« (Parmenides) - Lücke um Lücke hüpft, nimmt sich selbst aus, stutzt und unterbricht sich selbstverstimmt plötzlich und erzielt damit, daß die Zusammenverbundenheit der Untal-Intervalle nicht nur nicht verlorengeht, während und indem sie allenthalb ununterlaufen wirkt, sondern da wie dort überüberläuft zum Glück, daß es sie gibt -

Abb. 6: Egger 2017, 207. 
»quinen« öffnet sich ein Intervall der Hoffnung. Die vernommene Klage der Tiere wird mit einer möglichen Welt verbunden, in der Viehschellen und Schlachtungen nicht mehr existieren.

"Heirauch" im dritten Vierzeiler ist eine Verschmelzung aus dem Tirolischen »Hei« für »Heu« und »Weihrauch«. Aus dem Intervall zwischen der weltimmanenten Sphäre (dem Duft des dampfenden Heus) und der transzendenten Sphäre (dem Duft von Weihrauch) entsteht eine »Quaste aus gedrehten Fäden«: die Redevielfalt der Erzählung. Die Geschlossenheit der Strophen, die Einfachheit der Verse und die aus dem bäuerlichen Leben stammenden Bilder zitieren und dekonstruieren zugleich ein Volkslied.

Links neben dem Gedicht sind drei hängende Kordeln zu sehen, die aus vielen Fäden gedreht sind. Jede Kordel ist (durch unsichtbare Fäden) in fünf Abschnitte unterteilt. Indes, die Fäden dieser Zeichnung sind nur scheinbar Linien. Wer genau hinsieht, erkennt, dass sie aus vielen einzelnen Punkten bestehen, zwischen denen das weiße Nichts des Blattes sichtbar wird.

Die letzte Seite des Bandes ist randvoll mit Text gefüllt (s. Abb. 6.). Doch zieht sich ein vertikaler Bruch durch die Textfläche, von oben bis unten die ganze Seite in zwei Hälften teilend. Die feine Bruchlinie ist mit großem gestalterischen Geschick inszeniert: Sie ergibt sich (meistens) aus den wirklichen Spatien zwischen den Wörtern, zwischen Satzzeichen und Wörtern sowie (vereinzelt) aus unwirklichen, fingierten Spatien, die manche Wörter rein optisch öffnen (»Null leiter «, »Illustra tionen «, »Intarsi en «). Sie ist eine Störung, die sich durch die Rede zieht. Oder aber: Sie ist die Störung, um die herum die Rede entsteht. Sie verbindet Hälften, die es `eigentlich`nicht gibt, die das Ergebnis der künstlerischen Gestaltung sind. Als Wort-Bild (Figuren-Prosa, carmen figuratum) spiegelt sie alle Intervalle zusammen, die sich im Buch öffnen, sowohl die wirklichen (faktischen) als auch die unwirklichen (erdachten), die sich der poetischen Imagination verdanken.

Der poetologische Text ist der Schlüssel zu allen vorhergegangenen Seiten:

Soll, was der Fall sein kann, falsch sein? Kein Valeur, also verneint davon? Das areale Areal, welches mein Tempe-, Kidron-, Licenza- und Kampanertal lustriert, istert, vom Cañon der Novella durchschlitzt, Bruchlinie und »Null leiter ${ }^{30}$ einer voralpiden Gebirgsfaltung, woraus die ganze Zeit - ineinanderschneidtelnd - auf blätterte ${ }^{31}$ und so ungegenständig auseinanderfall'zt: mit Schalt-Intervallen, worin aber das Ganze und seine Teile auseinandertalen:

30 Durch dieses Wort zieht sich die Störungslinie.

31 Durch dieses Wort zieht sich die Störungslinie. 
Zwölf interim offene Intervall-Kapitel, durchrätselt von 365 lautgewordenen Gedanken (in Form von Worten und in Formen ohne Worte), ausge stanzt ${ }^{32}[\ldots .$.$] .$

(Egger 2017, 207)

Genannt wird gleich zu Beginn das Thema: die Un-Falschheit des Möglichen. Es folgen die literarischen Vorläufer des Un-Tals, nämlich die griechische Antike (das Tempetal ist das steile Durchbruchstal des Flusses Peneios zwischen dem Olymp und dem Ossagebirge in Thessalien), die jüdisch-christliche Tradition (das Kidrontal ist ein kleines Tal, welches die Altstadt und den Tempelberg von Jerusalem vom Ölberg trennt), die lateinische Antike, insbesondere die Poetik und der intellektuelle Witz eines Horaz (das Licenzatal ist ein Tal in Latium in der Nähe von Rom; hier stand die Villa des Horaz, die ihm Maecenas geschenkt hatte; in seinen Werken beschreibt Horaz oft die Landschaft dieses Tals); und die unbändige, mäandernde Fabulierlust von Jean Paul (eines seiner Werke trägt den Titel Das Kampaner Tal oder über die Unsterblichkeit der Seele, nebst einer Erklärung der Holzschnitte unter den 10 Geboten des Katechismus, 1798). Erklärt wird die Kulisse der Rede (das Tal der Novella), anschließend die Struktur des Buches: ein ıganzes Jahr, bestehend aus »[z]wölf interim offene[n] IntervallKapitel[n], durchrätselt von 365 lautgewordenen Gedanken«. Es sind »verbundene Wort-für-Wort Folgen voralpiner Substrate.« (Egger 2017, 207) Ein zur Hälfte wörtlich übernommenes, zur Hälfte im Egger-Sound fortgeführtes Horaz-Wort (mit Angabe der Quelle) nennt das Vorbild in puncto Originalität und legt zugleich die Freiheit im Umgang mit Quellen offen: »Ich habe meinen Weg, wo keiner mir voranging, selbst gebahnt, allein, und unentwegt, ginge ich durch Nichts, das ist, ins Leere. (Horaz, Ep. 1, 19)« (Egger 2017, 207) Ab »allein, und unentwegt ... « sind es (unverkennbar) Egger-Worte. Genannt (aber nur zum Teil erklärt) werden die sprachlichen Eigenarten der Novelle:

Wort für Wort (als Zwickmühle) grummelte im zähglühenden Substrat der rätischen Restund Trümmersprache: mit morphosyntaktisch glosenden Besonderheiten und selten verstandenen Konjunktiven und Aktionsarten, Kasus und infixen Tempus- und Aspektwechseln einer eben höheren deutschen Sprache, die hier am weitesten entwickelt, qua si ${ }^{33}$ aufgedeutscht erscheint: im offenen Buch ruminant aufgeblättert, ein room of rumor.

(Egger 2017, 207)

Das sprachliche Areal des Val di Non umfasst geologische und dialektale Störungslinien:

32 Durch dieses Wort zieht sich die Störungslinie.

33 Durch dieses Wort zieht sich die Störungslinie. 
Das Val di Non selbst zeichnet dieses Störungsbündel innerhalb des areallinguistischen Dial ektkontinuums ${ }^{34}$ vor, dessen Konnexität und Kontingenz vom Krimgotischen bis zum illy rischen, ${ }^{35}$ dolomitischen Fächer reicht und un-unterredend und-vebunden, instantan zutage tritt [...].

(Egger 2017, 207)

Auch der (oftmals selbstreferentielle) Witz der Egger’schen Rede nimmt hier Gestalt an:

Als als Tobel, der sich selber selbstlaut schluckt, wie diese Rumpeldipumpel-Ptyx-zer burzelten $^{36}$ Orks und Stilze durch ein Loch in einem Loch (ganz kugelig geformte, peristal tische ${ }^{37}$ Ungestalten) [...].

(Egger 2017, 207)

Sogar die Quellen mancher Illustrationen werden genannt:

D. h., alle Abbildungen wurden für die ses ${ }^{38}$ Buch gezeichnet; und manche gehen auf illustre Instanzen zurück, wie: Louis Agassiz (Felsengeburt, Wurmverknäuelung), John Ellis (Madreporaria, Similaun) oder die Mechanik der Sedimentbewegung im Fließrinnengefüge stehender Gewässer, Anastomosen, so wie ein ganzer Auftrieb von Protozoa (Dinoflagellates, Ciliata, Crinoidea, Peridineae) durch Georges Deflandre, Geza Entz, Alfred Giard, Charles A. Kofoid, Vilém Dušan Lambl).

(Egger 2017, 207)

Im letzten Satz schließlich des letzten Paratextes, an einer ssensiblen<, weil exponierten Stelle, steht, zusammengeschnürt (einer Kordel ähnlich), der Kern der Egger'schen Poetik:

Lücke um Lücke hüpft, nimmt sich selbst aus, stutzt und unterbricht sich selbstverstimmt plötzlich und erzielt damit, daß die Zusammenverbundenheit der Untal-Intervalle nicht nur nicht verlorengeht, während und indem sie allenthalb ununterlaufen wirkt, sondern da wie dort überüberläuft zum Glück, daß es sie gibt -

(Egger 2017, 207, Kursivmarkierung EDF)

Der Schlussakkord enthält das Glück. S. 207 ist poetologisches Selbstbekenntnis, Handreichung für die Leserinnen und Danksagung in einem. Es hilft, sich im Labyrinth des Bandes zu orientieren. Es deutet die Un-Menge der Fluchtlinien an, die, von den 365 Gedanken ausgehend, in alle Richtungen laufen. Der letzte Paratext ist ein Stück schillernder, geistvoller Prosa. Man kann ihn wörtlich nehmen und sich durch die Sprach- und Bildwelt von Val di Non führen lassen. Er kann aber auch (nicht aufgeschlüsselt und nicht-instrumentalisiert)

34 Durch dieses Wort zieht sich die Störungslinie.

35 Durch dieses Wort zieht sich die Störungslinie.

36 Durch dieses Wort zieht sich die Störungslinie.

37 Durch dieses Wort zieht sich die Störungslinie.

38 Durch dieses Wort zieht sich die Störungslinie. 
als rein akustisches Phänomen, als Schlussakkord einer gewaltigen Symphonie, angehört werden. Im ersten wie im zweiten Fall entfaltet er ein Stimmgetöse.

\section{Resümee}

Die genaue Lektüre der Paratexte sowie der ersten Seite der seigentlichen` Erzählung von Val di Non zeigt, wie bedacht und kunstvoll der Autor sein Buch konzipiert und komponiert hat. Es ist ein Buch über die Verbundenheit von Gegensätzlichem, über `das Ganze`, in dem alle Phänomene aufgehen. Bei allem Feuerwerk der Einfälle strahlt der Band eine erstaunliche Ruhe und Eleganz aus. Sie sind das Ergebnis eines bewussten, sorgfältig durchgeführten Plans, in dem nichts dem Zufall überlassen wird. Das virtuos geknüpfte Netz aus abertausenden Details verdankt sich in gleichem Maße überschäumender Phantasie wie großer Gelehrsamkeit und künstlerischer Ratio.

Ein scheinbar unentwirrbares Gemenge an Stimmen und Bildern entpuppt sich als ein polyphoner Wort-Bild-Gesang. Er ist eine Hommage auf den oberen Nonsberg, das Tal der Novella, die Sprachheimat des Autors und das >Ursprungsareal seiner poetischen Rede. In Val di Non schöpft Egger aus den Tiefenschichten der Sprache, der Erde, der Geschichte, des Mythos und der Religion (s)einer Berglandschaft. Sein poetischer Blick und sein Ohr vernehmen Differenzen (Intervalle), d. h. Nuancen, die dem ungeübten Betrachter verborgen bleiben. In der Offenheit der Intervalle aber ereignet sich poetische Intensität. Die `Fremdheit ` von Eggers Sprache ist, wie Deleuze wohl sagen würde, »eine Art Fremdsprache, die weder eine andere Sprache noch wiederentdeckter Dialekt, sondern ein AndersWerden der Sprache ist, eine Minorisierung jener großen Sprache, ein Delirium, das sie fortreißt, eine Hexenlinie, die aus dem herrschenden System ausbricht." (Deleuze und Guattari 2017, 16)

\section{Literaturverzeichnis}

Abraham, Ulf und Julia Knopf: Genres des BilderBuchs. In: BilderBücher. Theorie. Hrsg. v. Julia Knopf und Ulf Abraham. Baltmannsweiler 2014, 3-11.

Ausserer, Patrik: Die Geologie entlang der Gampenpassstraße. In: Die Straße über den Gampenpass. Geschichte, Landschaft, Kunst und Brauchtum. Hrsg. v. Gampenpasskomitee. Bozen 2015, 206-213.

Bachtin, Michail: Das Wort im Roman. In: ders.: Die Ästhetik des Wortes. Hrsg. v. Rainer Grübel. Aus dem Russ. übers. v. Rainer Grübel und Sabine Reese. Frankfurt a. M. 1979, 154-300. 
Cage, John und Tito Gotti: Alla ricerca del silenzio perduto. Il treno di John Cage. 3 escursioni per treno preparato / variazioni su un tema di Tito Gotti, di John Cage; con l'assistenza di Juan Hidalgo e Walter Marchetti. Hrsg. v. Oderso Rubini und Massimo Simonini. Bologna 2008.

Dalla Torre, Karl Wilhelm von: Die volksthümlichen Thiernamen in Tirol und Vorarlberg. Innsbruck 1894. Einsehbar unter: http://www.literature.at/viewer.alo?objid=886\&page= $1 \&$ from $=1 \&$ to $=9 \&$ viewmode $=$ fullscreen [20. Dezember 2012]

Deleuze, Gilles und Félix Guattari: Tausend Plateaus. Kapitalismus und Schizophrenie. Bd. 2. Aus dem Franz. übers. v. Gabriele Ricke und Ronald Voullié. Berlin 1992a.

Deleuze, Gilles: Differenz und Wiederholung. Aus d. Franz. v. Joseph Vogl. München 1992b. Deleuze, Gilles und Félix Guattari: Was ist Philosophie? Aus d. Franz. v. Bernd Schwibs und Joseph Vogl. Frankfurt a. M. 1996.

Deleuze, Gilles: Die Literatur und das Leben. In: ders.: Kritik und Klinik. Aus d. Franz. v. Joseph Vogl. 3. Aufl. Frankfurt a. M. 2015, 11-17.

Deleuze, Gille und Félix Guattari: Kafka. Für eine kleine Literatur. Aus d. Franz. v. Burkhart Kroeber. 10. Aufl. Frankfurt a. M. 2017.

Duden. Grammatik der deutschen Gegenwartssprache. Hrsg. u. bearb. v. Günther Drosdowski in Zusammenarb. m. Peter Eisenberg u. a. 5., völlig neu bearb. u. erw. Aufl. Mannheim, Leipzig, Zürich u.a. 1995.

DWB: Deutsches Wörterbuch von Jacob und Wilhelm Grimm. 33 Bände. Leipzig/Berlin 1854-1971. Zitiert nach: http://dwb.uni-trier.de/de/ [11. September 2020]

Egger, Oswald: Nichts, das ist. Gedichte. Frankfurt a. M. 2001.

Egger, Oswald: Nihilum album. Lieder \& Gedichte. Frankfurt a. M. 2007.

Egger, Oswald: Val di Non. Berlin 2017.

Früh, J.: Zur Etymologie von »Flysch« (m.), »Fliesse« (f.) u. »Flins« (m.). In: Eclogae Geologicae Helvetiae 8.2 (1903-1905), 217-220 [doi:10.5169/seals-156273].

Gampenpasskomitee (Hg.): Die Straße über den Gampenpass. Geschichte, Landschaft, Kunst und Brauchtum. Bozen 2015.

Gimbutas, Marija: The Living Goddesses. Berkeley, Los Angeles, London 2001.

Hesiod: Theogonie. Werke und Tage. Griech. u. dt. Hrsg. u. übers. v. Albert von Schirnding. München, Zürich 1991.

Heusler, Andreas: Das Rätsel vom Vogel federlos. In: Schweizerisches Archiv für Volkskunde = Archives suisses des traditions populaires 24 (1922-1923), 109-111. Zitiert nach:

29. Dezember 2020: Das Rätsel vom Vogel federlos (e-periodica.ch: https://www.e-perio dica.ch/cntmng?pid=sav-001:1922:24::354).

Jean Paul [Friedrich Richter]: Sämtliche Werke. 10 Bände. Hrsg. von Norbert Miller. Darmstadt 2000. [SW]

Johannes vom Kreuz (Juan de la Cruz): Aufstieg auf den Berg Karmel. Hrsg., übers. u. eingel. v. Ulrich Dobhan, Elisabeth Hense, Elisabeth Peeters. 2. Aufl. Freiburg, Basel, Wien 1999.

Kleinschmidt, Erich: Die Entdeckung der Intensität. Die Entdeckung einer Denkfigur im 18. Jahrhundert. Göttingen 2004.

Kollmann, Cristian: Germanismen im Appellativwortschatz des Noceromanischen (Nonsberg, Sulzberg). Teil II: Althochdeutsch, Mittelhochdeutsch, Neuhochdeutsch mit BairischÖsterreichisch und Tirolisch. Innsbruck 1999 (Diplomarbeit).

Kollmann, Cristian: Grammatik der Mundart von Laurein. Eine Laut- und Formenlehre aus synchroner, diachroner und kontrastiver Sicht. Stuttgart 2012. 
Kühebacher, Egon: Die Ortsnamen Südtirols und ihre Geschichte. Bd. 2: Die geschichtlich gewachsenen Namen der Täler, Flüsse, Bäche und Seen. Bozen 1995.

Kühebacher, Egon: Sprache und Namen im Dolomitenland. Beiträge zur Ortsnamenkunde Südtirols. Lichtbilder von Erika Hubatschek u.a. Wien 2007.

Kühner, Raphael: Ausführliche Grammatik der lateinischen Sprache. Bd. 2.1. Hannover 1878.

Kühner, Raphael: Ausführliche Grammatik der griechischen Sprache. Teil 2: Satzlehre. Bd. 2. Hannover, Leipzig 1904.

Lange, Wolfgang: Die Nuance. Kunstgriff und Denkfigur. München 2005.

Matsuyama, Daiko: The Role and the Present Significance of Koans. In: Handbook of Zen, Mindfulness, and Behavioral Health. Hrsg. v. Akihiko Masuda und William O’Donohue. Cham 2018, 67-75.

Mayröcker, Friederike: Das besessene Alter. Gedichte 1986-1991. Frankfurt a. M. 1993.

Menghin, Alois: Aus dem deutschen Südtirol. Mythen, Sagen, Legenden und Schwänke, Sitten und Gebräuche, Meinungen, Sprüche, Redensarten etc. des Volkes an der deutschen Sprachgrenze. Meran 1884. Siehe: https://diglib.uibk.ac.at/ulbtirol/content/titleinfo/ 778769 [20. Dezember 2012]

Moennighoff, Burkhard: Paradoxon. In: Metzler Lexikon Literatur. Begriffe und Definitionen. 3. Aufl. Hrsg. v. Dieter Burdorf, Christoph Fasbender und Burkhard Moennighoff. Stuttgart, Weimar 2010, 568-569.

Moser, Hans: Wörterbuch der Südtiroler Mundarten. In Zusammenarbeit mit Robert Sedalaczek. Innsbruck, Wien 2015.

Müller, Götz: Jean Pauls Ästhetik und Naturphilosophie. Tübingen 1983.

[N. N.] »Flysch«. In: Lexikon der Geowissenschaften. Hrsg. v. Christian Martin u. a. 6 Bde. Heidelberg 2000-2002. Siehe: https://www.spektrum.de/lexikon/geowissenschaften/ flysch/5098 [28. Dezember 2020].

[N. N.] »Magma«. In: Lexikon der Geowissenschaften. Hrsg. v. Christian Martin u. a. 6 Bde. Heidelberg 2000-2002. 28. Siehe: https://www.spektrum.de/lexikon/geowissenschaf ten/magma/9872 [28. Dezember 2020].

[N. N.]: "Störung«. In: Lexikon der Geowissenschaften. Hrsg. v. Christian Martin u. a. 6 Bde. Heidelberg 2000-2002. Siehe: https://www.spektrum.de/lexikon/geowissenschaften/ stoerung/15764 [31. August 2020].

[N. N.]: »Thetys vagina«. In: World Register of Marine Species. Hrsg. v. WoRMS Editorial Board. (http://www.marinespecies.org) at VLIZ. Accessed 2020-12-27.Siehe: http://www.marine species.org/aphia.php? $\mathrm{p}=$ sourcedetails\&id=166360 [28. April 2021].

Ortner, Lorelies: Benennung und Charakterisierung von Personen in den Sagen aus Tirol (Ignaz Vinzenz Zingerle). In: Literatur und Sprachkultur in Tirol. Hrsg. v. Johann Holzner, Oskar Putzer und Max Siller. Innsbruck 1997, 31-52.

Ryan, Marie-Laure: Possible Worlds. In: The living handbook of narratology (http://www.lhn. uni-hamburg.de/). Hrsg. v. Peter Hühn, Jan Christoph Meister, John Pier und Wolf Schmid. Hamburg 2013. Siehe: http://www.lhn.uni-hamburg.de/node/54.html [4. August 2020].

Schmitz-Emans, Monika und Christian A. Bachmann: Literatur - Künstlerbuch - künstlerisch gestaltetes Buch: Konvergenzen und Bündnisse. In: Bücher als Kunstwerke. Von der Literatur zum Künstlerbuch. Hrsg. v. Monika Schmitz-Emans und Christian A. Bachmann. Essen 2013, 7-13.

Schmitz-Emans, Monika: Religious discourse and metapoetic reflection in Jean Paul's novels: The »Rede des toten Christus «, the »Clavis Fichtiana«, and Kain's monologue in »Der Komet«. In: Neohelicon 42 (2015), 389-402. 
Schumacher, Stefan: Die rätischen Inschriften. Geschichte und heutiger Stand der Forschung. Innsbruck 1992.

Schütte, Wolfram: Zum 250. Geburtstag von Jean Paul [2013]. 4. August 2020: http://culturmag. $\mathrm{de} /$ litmag/wolfram-schutte-zum-250-geburtstag-von-jean-paul/68047.

Schwienbacher, Brunhild: Über den Ultner Dialekt. Struktur und Aufbau einer Tiroler Mundart. Lana 1997.

Staiger, Michael: Erzählen mit Bild-Schrifttext-Kombinationen. Ein fünfdimensionales Modell der Bilderbuchanalyse. In: BilderBücher. Theorie. Hrsg. v. Julia Knopf und Ulf Abraham. Baltmannsweiler 2014, 12-23.

Suprun, Anatolij P., Natalja G. Yanova und Konstantin A. Nosov: Zen Psychology: Koans. In: Journal of Russian and East European Psychology 51.5-51.6 (2013), 49-135.

Tomasek, Tomas: Das deutsche Rätsel im Mittelalter. Tübingen 1994.

Vermaseren, Maarten J.: The Miraculous Birth of Mithras. In: Mnemosyne 4.3/4.4 (1951), 285-301.

Vonbun, Franz Josef: Die Sagen Vorarlbergs. Mit Beiträgen aus Liechtenstein. Feldkirch 1950. Siehe: http://www.sagen.at/texte/sagen/oesterreich/vorarlberg/rheintal/eidechse.html [4. August 2020].

Vogl, Joseph: Über das Zaudern. 2. Aufl. Zürich, Berlin 2014.

Williams, James: Difference and Repetition. In: The Cambridge Companion to Deleuze. Hrsg. v. Daniel W. Smith und Henry Somers-Hall. Cambridge 2012, 33-54.

Zingerle, Ignaz Vinzenz: Sagen aus Tirol. Innsbruck 1850. 